\title{
Game Theoretic Research on the Design of International Environmental Agreements: Insights, Critical Remarks, and Future Challenges*
}

\author{
Michael Finus \\ Department of Economics, University of Stirling, Stirling FK9 4LA, Scotland, UK, \\ E-mail:Michael.Finus@stir.ac.uk
}

\begin{abstract}
In recent years, the number of publications that analyze the formation and stability of international environmental agreements (IEAs) using the method of game theory has sharply increased. This paper reports on some recent results that shall demonstrate the usefulness but also the limitation of game theory for the analysis of IEAs. It restricts attention to the class of non-cooperative membership models and focuses on the relation between different designs and the success of IEAs. Results are illustrated for the climate change problem with the empirical Stability of Coalitions (STACO) model developed by Dellink et al. (2004). Subsequently, some features of actual treaty-making not considered with this model are discussed with reference to the literature and their importance for future research is highlighted.
\end{abstract}

Keymords: Game theoretic research; international environmental agreements; recent results; critical review; agenda for future research.

FEL Codes: C72, D62, H41, Q25

\footnotetext{
* Parts of this paper have been written while I was a visiting fellow at the Universidade do Algarve, Faro, Portugal. I particularly like to thank Prof. Pedro Pintassilgo for the invitation and the many interesting and inspiring discussions. I have also benefited from numerous discussions with Prof. Alfred Endres, University of Hagen, Prof. Ekko van Ierland and his research group at the University if Wageningen and Professor Johan Eyckmans, Europese Hogeschool Brussels that have shaped my view on the subject. Particular thanks go to Henk Folmer, Tom Tietenberg, and two anonymous referees for their critical remarks and suggestions for improvement. Needless to say, any remaining shortcomings have to be blamed on me.
}

ISSN 1932-1465; DOI 10.1561/101.00000011

(C) 2008 Michael Finus 


\section{INTRODUCTION}

Since the early papers by Barrett (1994), Carraro and Siniscalco (1993), Chander and Tulkens (1992), Hoel (1992), and Mäler (1989) there is a sharply increasing number of publications that analyze the formation and stability of international environmental agreements (IEAs) using game theory. ${ }^{1}$ This is not surprising for at least two reasons.

First, environmental problems with an international dimension become more and more threatening and receive an increasing coverage in politics, the media and the public. Topics range from the loss of biological diversity, the depletion of the ozone layer and more recently the concern about the impacts of global warming. All these environmental problems make joint and coordinate action at a global scale necessary in order to prevent the most severe damages to nature and mankind. However, despite good intentions and many public statements by politicians, progress is often slow: free-riding is still the most important obstacle for successful IEAs. ${ }^{2}$ In order to mitigate free-riding, it is important to understand the strategic considerations of the actors causing transboundary environmental externalities for which game theory is an ideal method.

Second, game theory is a mathematical method that studies the interaction between agents based on behavioral assumptions about the preference of agents and makes prediction about the outcome of these interactions by applying various equilibrium concepts. Thus, game theory seems to be an ideal tool to study IEAs as they provide a public good with transboundary externalities from which nobody can be excluded. In particular, the use of non-cooperative game theory seems suggestive, presuming the absence of a "third party" able to enforce contracts: though global rationality would call for cooperation, individual rationality often stipulates free-riding behavior since there is no supranational institution that can enforce participation in IEA and compliance with agreed obligations.

However, there still maybe some scholars that do not share my enthusiasm for game theory. For instance, they could point out that game theoretic analyses are being based on too abstract models and assuming too much about the rationality of agents. As to the first point, I would argue that abstraction is a general phenomenon of models in social

1 For a survey see for instance Folmer and de Zeeuw (1999, 2000), Folmer and van Mouche (2000), Finus (2001, 2003a), Wagner (2001), and Barrett (2003), Bohringer and Finus (2005).

2 Climate change is a good point in case. The Framework Convention on Climate Change called for actions to prevent severe damages to the climate. However, this treaty is only a declaration of good intentions without specific abatement obligations, which may explain that it has been signed by almost all countries in 1992. In 1997, only 38 states accepted emission ceilings within the Kyoto Protocol. It went not into force until 2002, after the USA had withdrawn their signature and several concessions to the original abatement targets had been granted to various participants. Current emission levels suggest that many signatories will not be able to meet even these modest obligations in the commitment period 2008-2012 (e.g., Böhringer and Finus 2005). Other examples which prove that participation and compliance is a problem when dealing with global environmental problems are provided in Barrett (2003) and Finus (2003a), Section 2. 
sciences. On the one hand, abstraction is necessary to unveil the gist of the problem. Moreover, including too many aspects and layers of a problem renders a model too complex for deriving sensible conclusions. On the other hand, it is certainly true that the simplifying assumptions have to be critically checked whether they really capture the heart of the problem under investigation. In the course of such a review, it seems wise to replace simplifying by more realistic assumptions only sequentially in order to be able to handle such complications.

As to the second point, the definition of rationality becomes important. If irrationality means that agents do not base their actions exclusively on economic variables in a narrow sense, I would certainly agree with this critique. After all, models that define rationality in such a narrow sense frequently fail to explain important real world phenomena. However, if irrationality means that agents' behavior is not related to their preferences, which may include a preference for some notion of equity and fairness, I believe a scientific analysis is not possible anymore. In particular, the question arises which assumption should replace rationality and on which grounds it can be founded.

In this paper, I report on some selected results that have been obtained with recent developments in game theory. The aim is three-fold. First, I would like to demonstrate how models can account for more realistic assumptions and what the insights from such an analysis are. Second, I want to show that there is still sufficient room for developing current models further within the boundaries of rationality in a wider sense. Third, I want to identify the limitations of current models, explaining the challenges for future research, hoping to initiate new ideas for improvement.

In the following, I proceed as follows. In Section 2, I will first give a brief overview of game theoretic models on IEAs that deal with the problems of participation (membership models) and compliance (compliance models). Then I describe membership models in more detail as this is the class of games to which I will restrict myself in this paper. In Section 3, I analyze how the design of IEAs is related to their success using results derived from the Stability of Coalition Model (STACO-model). The STACO model comprises an empirical climate module with twelve world regions and a game theoretic module computing stable coalitions - the technical term for stable environmental agreements. In Section 4, I discuss some aspects not considered in the STACO model but which may prove important for future research. Overall, the discussion will be much centered around emission problems, in particular, related to climate change.

\section{THE THEORY OF COALITION MODELS}

\subsection{Introduction}

Up to now, no coalition model captures all aspects of coalition formation. This concerns not only some institutional details of treaties (e.g., instruments of implementation like

emission taxes or permits or exceptions and transition periods granted to least devel- 
oped countries regarding implementation of abatement targets and time tables) and political aspects of negotiations (e.g., intervention of various interest groups in favor or against high abatement targets), but also the fundamentals of the game theoretic analyses of IEAs - the two types of free-rider incentives (Finus, 2003a). The first type refers to the incentive not to participate in an IEA; the second type to the incentive not to comply with the obligations agreed upon in an IEA. Membership models focus on the first type of free-rider incentive. Implicitly, they assume that once a country joins an agreement it will comply with the agreed treaty obligations. Thus, compliance is exogenous. In contrast, compliance models concentrate on the second type of free-rider incentive, starting from the exogenous assumption that some coalition has formed and test whether treaty obligations can be enforced with credible threats to sanction non-compliance. Hence, I conclude that the current models are limited in their scope and that there is a need to develop models that capture both types of free-rider incentives. $^{3}$

Moreover, membership and compliance models have in common that they make some exogenous assumptions about the institutional details of the design of an agreement. These assumptions concern for instance the choice of the aggregate level of abatement implemented within a coalition, the allocation among its members, the amount and direction of transfer payments among coalition members. Thus, despite many models comparing the outcome of different institutional arrangements, one has to be aware that not all choices are endogenized. This is not a critique, as the complexity of these models requires some simplification, but simply an acknowledgment of the limitation of these models. It is also important to point out that almost all models assume the players in the game to be countries. That is, the political decision process within a country is neglected and the representatives of a country de facto behave as benevolent dictators in the sense of welfare economics. I will later comment on this assumption in Section 4.

\subsection{Membership Models}

Two strands of membership models for the analysis of IEAs have been distinguished in the literature (Tulkens, 1998, Finus, 2003a): cooperative and non-cooperative. Contributions using cooperative game theory have predominantly used the stability concept of the core; those using non-cooperative game theory have mainly used the concept of internal and external stability and modifications of it. ${ }^{4}$ The textbook definition suggests

3 The relation between both types of models is analyzed in Barrett (1999). De Zeeuw (2007) may be seen as a preliminary attempt to include participation and compliance in one model.

4 The cooperative approach in environmental economics was initiated by Chander and Tulkens (1992) and the non-cooperative by Barrett (1994), Carraro and Siniscalco (1993), and Hoel (1992). Subsequent papers are reviewed in Finus (2003a). Roughly speaking, the core requires that no subgroup of countries can raise a valid objection against a coalition and the payoffs each member receives (called an imputation). Since the grand coalition generates the largest cooperative surplus in the context of externalities, only the grand coalition can be in the core. Hence, the test for "corestability" comes down to test whether for a particular allocation of the cooperative surplus in the grand coalition (i.e., a coalition of all countries) a subgroup of countries could deviate by obtaining 
that cooperative in contrast to non-cooperative game theory assumes a third party that can enforce an agreement. Following this definition was to imply that cooperative game theory models would not be suited to analyze the problems of cooperation in international pollution control. However, I believe this categorization of models is misleading and the implied conclusion is premature for two reasons. First, also the cooperative models test whether coalition members have an incentive to leave the coalition, considering reactions of the remaining players that imply an implicit punishment. For instance, the $\gamma$-core assumes that once a group of countries leaves a coalition, the remaining countries play their non-cooperative emission strategy. Second, also most non-cooperative models make heroic assumptions about the sense for cooperation among coalition members when choosing their emission strategies (see more on this below). Moreover, both strands assume full compliance with abatement obligations once a coalition has formed, which is typically associated with the notion of cooperative game theory.

Regardless whether cooperative and non-cooperative game theory is an adequate terminology, and ignoring the challenge to find a better one, I think there are at least three reasons to argue that the non-cooperative approach is superior.

First, taking the fact of a missing supranational authority seriously in models means to undertake the effort to include as many non-cooperative elements as possible into a game theoretic model on IEAs. In particular, consistency requires that the behavior of countries or their representatives is derived from individual optimization. However, it is important to point out that this does not preclude that countries are interested in cooperation. Even if agents behave selfishly in a strict sense, in the presence of externalities, individual optimization requires some form of cooperation or coordination. Moreover, ethical and moral motives can be considered by making it part of individuals' objective functions, which are frequently called payoff functions in the game theoretic literature.

Second, recent developments in non-cooperative membership models have shown that this approach is more general and more transparent in terms of assumptions by separating the rules of coalition formation from stability concepts (see Bloch, 2003, Finus, 2003a, 2003b for overviews). This more general approach also allows replicating the assumptions and results of the cooperative approach. ${ }^{5}$

\footnotetext{
a larger aggregate payoff among the deviators. Whether such an "objection" pays depends (apart from the surplus sharing rule) on the reaction of the non-deviating countries which I call implicit punishment and for which I provide examples below. Internal and external stability means that no single country likes to join or leave a coalition, given that the remaining players do not change their membership strategy and adjust their abatement strategy in their own best (myopic) interest. This concept will be explained in more detail below. The interested reader is referred to Finus (2003a) for an extensive discussion of the core and internal \& external stability concept.

5 For instance in Finus and Rundshagen (2006a) it is shown that the $\gamma$-core resembles strong Nash equilibrium coalition structures in a game which they call exclusive membership H-game. This alternative approach makes it for instance transparent that a stable coalition structure has to be immune not only to a deviation by a single player but also by any subgroup of players and this is associated with the stability concept. A deviation implies that the coalition to which the deviators belong but also all other other coalitions break apart. This reaction is associated with the membership rule.
} 
Third, the potential for explaining real world phenomena of IEAs is much higher for the non-cooperative than for the cooperative approach (as used up to now). By definition, in the context of externalities, only the grand coalition (i.e., the coalition of all countries) implementing the socially optimal abatement target can be stable in the sense of the core. ${ }^{6}$ As most papers (e.g., Chander and Tulkens, 1995, 1997) show, this is indeed the case provided an adequate transfer scheme is implemented. The reason is that the implicit punishment implied by the core concept is very strong. For instance, the $\gamma$-core assumes after a group of countries have deviated that all other players play their Nash equilibrium abatement strategy. Other core concepts assume even stronger punishments like minimax or maximin strategies (see Tulkens, 1998, Finus, 2003a for details). Ignoring the discussion whether this punishment is credible or whether alternative assumptions (e.g., all non deviating players could choose abatement strategies which are optimal in their joint interest) are more convincing, it is evident that current versions of this concept cannot contribute much to explain the existing problems of global environmental cooperation. Of course, one may point out that the core is a normative and not a positive concept. However, then the question arises whether we still and repeatedly have to be reminded that the benchmark to solve transboundary externalities is full cooperation. ${ }^{7}$ I suppose this is known also to non-game theorists and is not even debated among environmental and ecological economists as well as scientists of other disciplines. What seems controversial is the identification of the problems that prevent full cooperation or even partial cooperation and the measures to overcome these obstacles. A small contribution from a (non-cooperative) game theorist's point of view is offered below.

\subsection{The Construction of Non-cooperative Membership Models}

Table 1 shows the basic structure of non-cooperative membership models. In the first stage, countries decide upon their participation; in the second stage, they decide upon abatement and possible transfers. The decision about participation leads to a coalition structure, which is a partition of countries in disjoint sets. ${ }^{8}$ For given assumptions about

See footnote 4.

It certainly has to be argued that the normative merit of the cooperative approach lies in searching for optimal transfer schemes in order to mitigate free-rider incentives. This merit becomes apparant when noting that the Chander and Tulkens sharing rule proposed in Chander and Tulkens (1995, 1997) has been applied for instance in Barrett (2001), Eyckmans and Finus (2006a, 2006b) and has inspired the development of similar transfer rules for instance in Eyckmans and Finus (2004) in the context of the non-cooperative approach.

8 This means that a coalition structure comprises of coalitions. A coalition with only a single country is called singleton. Henceforth, I only use the term "coalition" for a non-trivial coalition of at least two countries. In non-technical terms, this is referred to as an agreement. If all countries are singletons, I call this the singleton coalition structure and if all countries form one coalition, I call this the grand coalition. 
Table 1. Structure of coalition formation in membership models*

\section{Stage: participation}

Sequence

$\underline{\text { Simultaneous }}$

Agreements

Membership

$\underline{\text { Single }}$

2. Stage: abatement and transfers

Sequence Simultaneous (Cournot)

Abatement Joint welfare maximization

\begin{tabular}{lc}
\cline { 2 - 2 } Transfers & $\frac{\text { (Efficient) }}{\text { No }}$ \\
Payoffs & $\frac{\text { Objective }}{\text { Social planner }}$ \\
$\frac{\text { Material }}{\underline{\text { Certain }}}$
\end{tabular}

Sequential

No revision of members revision of members

Multiple

Exclusive

Majority Unanimity

${ }^{*}$ Base assumptions are underlined, alternative assumptions as reported in Tables 2, 3, 4, and 5 in Section 3 are indicated italic. All other alternative assumptions are discussed in Section 4.

the decisions in the second stage, roughly speaking, a coalition structure is called stable if no country has an incentive to revise its participation decision. ${ }^{9}, 10$

Within each stage, different assumptions can be made. I first describe the archetype of non-cooperative membership models, which I call henceforth the base model, and of which the assumptions are underlined in Table 1 to which I henceforth refer to as the base assumptions. The base model assumes that countries simultaneously decide whether to join an IEA. This is a one-shot decision. Hence, if a model considers a dynamic payoff

9 In the context of the archetype of coalition model that I describe below, this stability concept has been called internal and external stability following d'Aspremont et al. (1983). That is, no member has an incentive to leave the coalition (i.e., agreement) to become a singleton, and no outsider has an incentive to join the coalition. This corresponds to a Nash equilibrium in member strategies. There are also more sophisticated equilibrium concepts. However, I ignore these technical refinements in the following because they are of minor applied relevance. See for instance Bloch (2003) and Finus (2001) overviews. Probably one of the most interesting conceptual extensions is the concept of farsighted stability as discussed in Diamantoudi and Sartzetaki (2007), Eyckmans (2003) and Ray and Vohra (1999). Roughly speaking, different from internal \& external stability, players take all possible chain reactions into account when deviating where reactions are not only optimal in a myopic sense but in a farsighted sense.

10 Note that the singleton coalition structure is stable in the sense of a Nash equilibrium by definition. Suppose all countries announce not to join the agreement, then a deviation by a single country (announcing to join the agreement) makes no difference - this requires at least a deviation by two countries. 
structure (as for instance the climate models reported in Section 3.1), a one-shot decision has to be based on discounted payoffs. Moreover, the base model assumes that there is only a single agreement where those countries that do not join the agreement remain as singletons (frequently called non-signatories in the literature); all other countries are members of the agreement (frequently called signatories in the literature). Nobody can be denied the access to the agreement, which is termed open membership.

Once a coalition has formed, it is assumed that all countries simultaneously choose their abatement levels, which is termed the Cournot-assumption in the literature. Coalition members choose their abatement as to maximize the aggregate payoff to their coalition, every non-member maximizes its own payoff. This means that coalition members internalize all externalities within their coalition, i.e., abatement is efficient within the coalition, but they ignore the externalities imposed on countries outside their coalition. Specifically, the coalitional abatement level is optimal for the coalition and the allocation among its members is cost-effective. ${ }^{11}$ Hence for this assumption if the grand coalition were to form, it would implement socially optimal abatement levels. If no coalition formed (i.e., the singleton coalition structure formed), this would correspond to non-cooperative abatement levels, also frequently called Nash equilibrium. Any coalition comprising more than one but less than all members may be regarded as partial cooperation. The base model assumes no transfers to correct for a possible asymmetric welfare distribution. Moreover, the decisions in the second stage are taken by representatives acting like social planners of individual countries; they are only based on costs and benefits from abatement (material payoffs), which are known with certainty and have been objectively estimated based on current scientific evidence.

In the following, I consider modifications of the base assumptions. In Section 3, I concentrate on those alternative assumptions for which results have been obtained with the STACO model. In Section 4, I discuss all remaining alternative assumptions listed in Table 1.

\section{RESULTS FROM THE STACO MODEL}

\subsection{Introduction}

In recent years, a couple of climate models have been used in order to study the prospects of cooperation. Examples include for instance Babiker (2001), Tol (2001), Böhringer and Löschel (2006), Buchner and Carraro (2005a), Kempfert (2005), and Guo et al. (2006). Most of these models are computable general equilibrium (CGE) integrated assessment models that capture the feedback between the economy and damages from climate change. In order to study stability of agreements, these models have to be linked to a game theoretic module of coalition formation. For instance, the CLIMNEG World Simulation model (CWS model) is a modification of the RICE model by Nordhaus and Yang (1996) and stable coalitions are determined with algorithms programmed with the

11 With coalitional abatement I mean the aggregate abatement level of the coalition. 
software package GAMS (e.g., Eyckmans and Finus (2006a) and Eyckmans and Tulkens (2003)).

For obvious reasons, CGE-models have been subjected to much criticism, starting from their assumptions about parameter values, the simple way in which they capture the climate and many other things (Scrieciu, 2006). I will not challenge this criticism at this stage; in fact will add some other points in Section 4. Instead, I want to point out that as long as we are not capable of solving most of the interesting coalition models analytically, we have to rely on simulations. Hence, the only question remains whether simulations should be based on some scientifically estimated parameters according to the current state of the art or whether some arbitrary parameters should be cooked up. Given this limited choice, I would opt for the first possibility. However, although these climate models produce quantitative results, by and large, only qualitative conclusions should be derived and this always with a grain of salt.

In the following, I present results obtained with the STACO model ${ }^{12}$ as this allows me to draw on the largest set of simulations obtained for different treaty designs but for the same set of parameter values. Compared with most other climate models, the STACO model is richer in that the world is divided not only into 6 but 12 world regions. Clearly in order to capture the incentives of individual countries for cooperation, the larger the set of countries, the more accurate can these incentives be studied. Regions in the STACO model include USA, Japan, European Union (EU-15), Other OECD countries (O-OECD), Central and Eastern European countries (EE), Former Soviet Union (FSU), Energy exporting countries (EEX), China, India, Dynamic Asian economies (DAE), Brazil and "Rest of the world" (ROW). ${ }^{13}$ As with most coalition models, the (one-shot) decision about membership is based on discounted payoffs. However, in contrast to other climate models, STACO is simpler by restricting the emission path to be constant over time. ${ }^{14}$ Nevertheless, all qualitative conclusions upon which I report below are confirmed by the results derived with the CWS model - a fully-fledged CGE-model. ${ }^{15}$ Moreover,

12 This model has been developed by Dellink et al. (2004). The subsequent results are compiled from Finus et al. (2004, 2005, 2006), Weikard et al. (2006), and Altamirano-Cabrera et al. (2008).

13 EU-15 comprises the 15 countries of the European Union as of 1995. O-OECD includes among other countries Canada, Australia, and New Zealand. EE includes for instance Hungary, Poland, and Czech Republic. EEX includes for example the Middle East Countries, Mexico, Venezuela and Indonesia. DAE comprises South Korea, Philippines, Thailand, and Singapore. ROW includes for instance South Africa, Morocco and many countries in Latin America and Asia. The categorization follows Babiker et al. (2001).

14 The bias introduced by this assumption is of minor importance as long as the decisions about membership is a one-shot decision and based on discounted payoffs. (It would be inappropriate for instance when the interest would be on studying optimal emission paths over time or analyzing a dynamic coalition formation process as in Rubio and Ulph (2007).) Note that in the STACO model overall magnitudes about accumulated emissions are calibrated such that they are in line with those of RICE.

15 See Eyckmans and Finus (2006a, 2006b, 2007) where the issues (a) single versus multiple coalitions, (b) open versus exclusive membership, and (c) various transfer schemes, which I discuss subsequently, are also considered. Only the issue efficient abatement versus bargaining has not been considered with the CWS model. 
in all papers mentioned under the STACO and CWS model in footnotes 12 and 15, respectively, sensitivity analyses have been conducted which confirmed all qualitative conclusions. This points to the robustness of qualitative conclusions.

\subsection{Results}

\subsubsection{General Observations}

In order to disucss some general observations, the reader is referred to Table 2. At this stage it suffices to note that various coalition structures are listed in column 1 with associated global abatement and global welfare in column 8 and 9 , respectively.

In the presence of externalities, the potential gain from cooperation can be large. This is evident for instance by showing that global welfare in the global optimum is three times larger than in the Nash equilibrium. ${ }^{16}$ But also partial cooperation can make a difference. For instance, a coalition of industrialized countries could raise global welfare by more than 50 percent compared to no cooperation which drops to 35 percent without the United States. It is also evident that not only the sheer number of participants is important for global welfare but also the identity of membership. For instance, a coalition of energy exporting countries (EEX) and China leads to a higher global welfare than a coalition between Former Soviet Union (FSU), Brazil, and ROW. Generally, the importance of the identity for cooperation can be linked to two effects. Countries with a flat marginal abatement cost curve, like China, the United States, and India in this model, keep abatement costs low in a given coalition. The reason is that China and India produce their goods relatively dirty and could therefore reduce their greenhouse gas emissions at low cost. But also the United States has plenty of opportunities for energy saving or energy substitution technologies at relatively low cost. Countries with high marginal benefits from global abatement, like EU-15, United States, and Japan in this model, push for high coalitional abatement in a given coalition from which not only coalition members but also non-members benefit.

\subsubsection{Open versus Exclusive Membership and Single versus Multiple Coalitions}

We consider now the first set of alternative assumptions as displayed in Table 2. Columns 2 to 7 indicate stable coalitions where " $\mathrm{n}$ " stands for not stable, " $\mathrm{y}$ " for stable and "_" stands for not defined. "OM" means open membership, "EM-MV" means exclusive membership with majority voting and "EM-UV" refers to exclusive membership with unanimity voting. Under open membership players are free to join any coalition, under exclusive membership this is only possible if a majority (EM-MV) or all (EM-UV) are in favor of accession (i.e., it raises the members' payoffs). For each of these membership rules, a version is considered where only a single coalition can form, denoted by $S$, and a

16 In most CGE-models this difference is usually smaller in relative terms. See for instance Eyckmans and Finus (2006a) and Nordhaus and Yang (1996). 


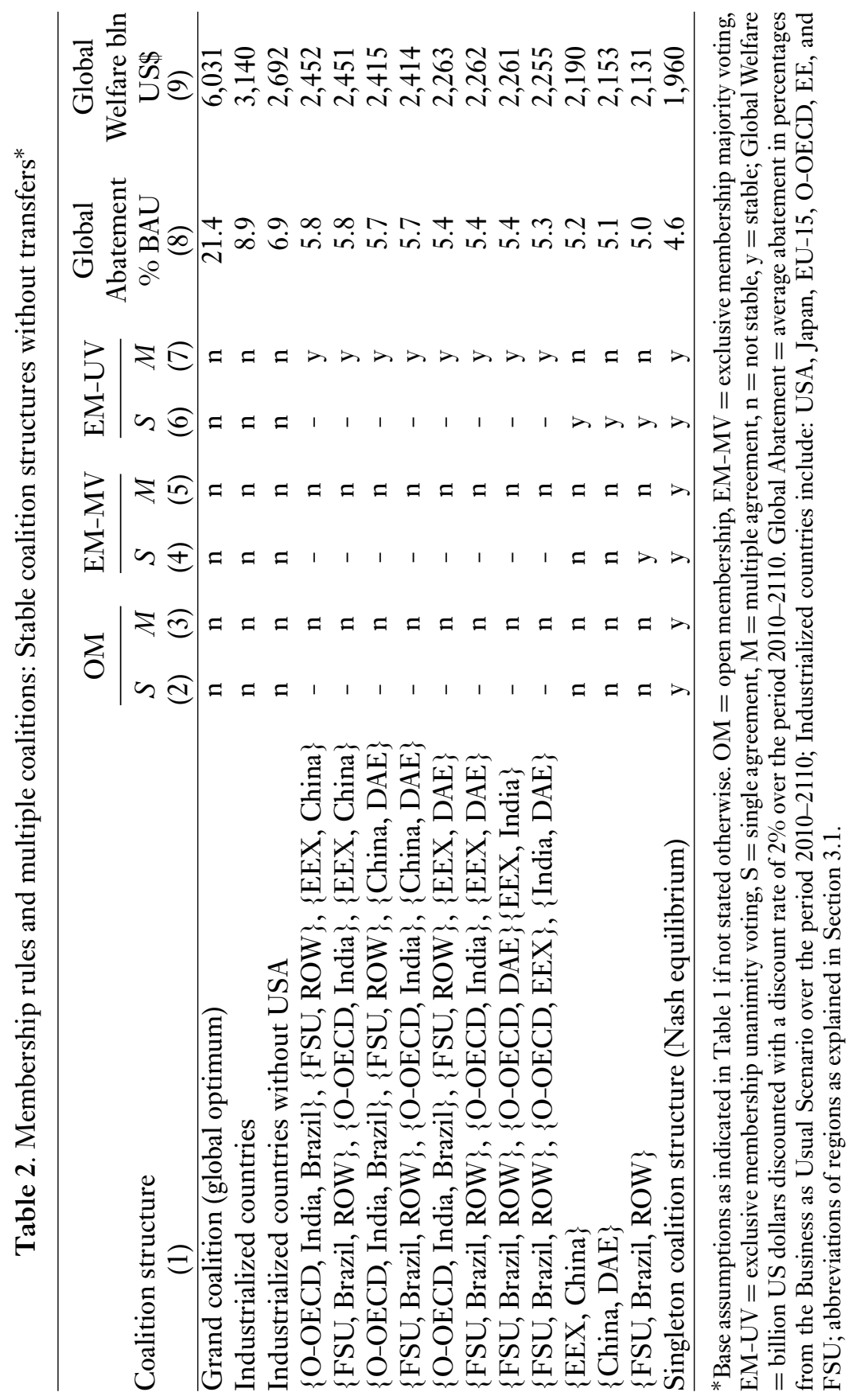


version where multiple coalitions can form, denoted by $M$. Hence the base assumptions are displayed in column 2 . In the sequel, I first assume a single coalition and analyze the issue open versus exclusive membership. Then I move on to multiple coalitions.

For this model, no coalition is stable for the base assumptions (see column 2). This changes with exclusive membership (see columns 4 and 6 ). In the example, majority voting leads to one stable coalition (see column 4 ) and unanimity voting implies three stable coalitions (see column 6). This goes along with higher global welfare and higher global abatement. If we allow for multiple coalitions (i.e., move from column 6 to 7), then for unanimity voting the success of cooperation improves even more. ${ }^{17}$

For the understanding of these results, it is helpful to note the following relations. Given that regions in this model have a very heterogeneous cost-benefit structure, in the absence of transfers, an efficient allocation of abatement duties within a coalition of heterogeneous partners leads to an asymmetric distribution of the gains from cooperation. This may imply that even some members are worse off than without cooperation. For instance, in most coalitions of which China is a member of a coalition, she has to contribute much to the joint abatement level (because of her flat marginal abatement cost curve), but benefits only little (because of low marginal benefits). In contrast, a region like the EU-15 contributes little to joint abatement (because of her steep marginal abatement cost curve), but benefits much (because of high marginal benefits). Thus, if at all, only coalition structures with coalitions that are comprised of members with a similar cost-benefit structure can be stable. Otherwise, a disadvantaged coalition member would simply leave the coalition. That is, internal stability of a coalition would be violated. It is for this reason that regardless of the treaty design (open versus exclusive membership, single versus multiple coalitions), there is no stable coalition including the major industrialized regions, like United States, EU-15, and Japan, and at the same time non-industrialized regions, like China, India, and ROW.

By the same token, advantaged countries have an incentive to join a coalition. That is, external stability would be violated. It is this last feature which explains why exclusive membership can make a difference compared to open membership. Not surprisingly, unanimity voting makes it easier than majority voting to keep advantaged countries out. For instance suppose there is a coalition $S$ and an outsider joins such that coalition $S \cup\{i\}$ forms. If this was to the disadvantage to the members of $S$, then they would leave

17 The idea to consider multiple coalitions in the context of IEAs goes back to Carraro (2000). An analytical analysis of single versus multiple coalitions in the context of symmetric countries under various assumptions about membership rules is conducted in Carraro and Marchiori (2003), Finus (2003b), and Finus and Rundshagen (2003). These papers confirm the superiority of multiple compared to a single agreements as this is also done by Asheim et al. (2006) in a compliance model. A different conclusion is reached in Bosello et al. (2003) and Buchner and Carraro (2005b) with the FEEM-RICE model. However, this seems to be due to some bizarre assumptions about the abatement level and allocation chosen within coalitions. For instance, Bosello et al. (2003) report that no multiple coalition structure is coalitionally rational (which they call weakly profitable). This means that the aggregate payoff of a group of countries decreases when they cooperate. This result is even more surprising because in a multiple coalition setting coalition members should benefit from the abatement activities of other coalitions. 
coalition $S \cup\{i\}$, i.e., coalition $S \cup\{i\}$ would not be internally stable. In other words, indirectly, exclusive membership helps to internally stabilize coalitions which leads to more stable coalitions.

For a single agreement, the participation decision is only yes or no. Due to strong freerider incentives, the decision is often no and hence only small and few coalitions are stable if at all. Hence, if a country does not want to join the main crowd, it would opt to remain a singleton. Now with multiple coalitions, it has a second option - forming another agreement with like-minded countries. For instance, the coalition of FSU, Brazil, and ROW is stable for exclusive membership and unanimity voting if only a single agreement can be formed (see column 6). If multiple coalitions are possible, other regions have an incentive to form their own agreement. Hence, the coalition structure with only a coalition of FSU, Brazil, and ROW is no longer stable. However, five other coalition structures are stable including a coalition with these three regions.

Taken together, Table 2 allows for two major policy conclusions. First, the open membership rule as applied in almost every international environmental treaty should not be taken for granted. Club good agreements (e.g., NATO, European Union, and WTO) may not only enjoy a higher stability and success because the benefits from contributions are exclusive to members (which is different for IEAs, which can be viewed as public good agreements), but also because accession is limited through majority or unanimity voting. As explained above, this helps to stabilize coalitions. Put differently, the requirement to take decisions by consensus (which is an integral feature of exclusive membership) may not always be an obstacle for successful cooperation - a conclusion that will be confirmed in a slightly different context below.

Second, the effort to get as many countries as possible into one "climate boat" may not be the best strategy in the presence of free-rider incentives. Allowing for separate agreements among regions that have similar interests may foster the success of international agreements. In this light, the position of the United States only to ratify the Kyoto Protocol if developing countries would also join the protocol and take on climate responsibility is open to criticism. ${ }^{18}$ However, their announcement in the aftermaths of their withdrawal that they would pursue their own climate policy cooperating with countries of similar interests may be viewed less critically. At least as an intermediate step, multiple agreements may be useful on the way to a global treaty as this is often the case with regional trade agreements that lead to more comprehensive agreements at later stages, for instance under the umbrella of the WTO.

\subsubsection{Transfers}

Table 3 illustrates the role of transfers. In order to separate effects, all other base assumptions are retained (i.e., single agreement, open membership). Generally, transfers can

18 In 1997, the US Senate unanimously passed the Byrd-Hagel resolution, which makes "meaningful" participation of developing countries a conditio sine qua non for ratification (The Byrd-Hagel Resolution, US Senate, June 12, 1997, 105th Congress, 1st Session, Senate Resolution 98). 
Table 3. The role of sharing scheme: Stable coalitions with transfers*

\begin{tabular}{lccc}
\hline \begin{tabular}{c} 
Transfer scheme \\
\multicolumn{1}{c}{$(1)$}
\end{tabular} & $\begin{array}{c}\text { Coalition } \\
\text { members } \\
(2)\end{array}$ & $\begin{array}{c}\text { Global abatement } \\
\text { \% BAU } \\
(3)\end{array}$ & $\begin{array}{c}\text { Global welfare } \\
\text { bln US } \$ \\
(4)\end{array}$ \\
\hline Global Optimum & Grand coalition & 21.4 & 6,031 \\
(1) GDP & EU-15, China & 7.3 & 2,942 \\
(2) Emissions & USA, EE, EEX, & 8.6 & 3,418 \\
& China & & \\
(3) Equal Sharing & EE, China, India & 5.9 & 2,499 \\
(4) Ability to Pay & China, India & 5.5 & 2,334 \\
(5) Inverse Emissions & EE, Brazil & 4.6 & 1,981 \\
& China, Brazil & 4.8 & $2,059\}(2,020)$ \\
(6) Population & EEX, China & 5.2 & 2,190 \\
Nash Equilibrium & Singleton coalition & 4.6 & 1,960 \\
& structure & & \\
\hline
\end{tabular}

*Base assumptions as indicated in Table 1 if not stated otherwise. For the general construction of outcome-based transfer schemes, see footnote 20 . The weights for the six transfer schemes are defined as follows: GDP: $\lambda_{i}=\mathrm{GDP}_{i} / \sum_{j \in S} \mathrm{GDP}_{j}$; Emissions: $\lambda_{i}=E_{i} / \sum_{j \in S} E_{j}$; Equal Sharing: $\lambda_{i}=1 / \# S$; Ability to Pay: $\left(\mathrm{GDP}_{i} / \mathrm{POP}_{i}\right)^{-1} / \sum_{j \in S}\left(\mathrm{GDP}_{j} / \mathrm{POP}_{j}\right)^{-1}$; Inverse Emissions: $\lambda_{i}=E_{i}^{-1} / \sum_{j \in S}\left(E_{j}\right)^{-1}$; Population: $\lambda_{i}=\mathrm{POP}_{i} / \sum_{j \in S} \mathrm{POP}_{j}$ with GDP $=$ gross domestic product, $E=$ BAU-emissions, $\# S=$ size of coalition $S, \mathrm{POP}=$ population; all values refer to 2010, see Weikard et al. (2006) for details. Abbreviations of regions as explained in Section 3.1. \# = no stable coalition. Global Abatement and Global Welfare as defined in Table 2.

be implemented in many ways. For instance, they can be paid in cash, can be designed as technological transfers or be part of political concessions in other policy fields (often referred to as issue linkage). I consider here only monetary transfers and only report on outcome-based rules. ${ }^{19}$ That is, the total surplus of cooperation within a coalition is distributed according to weights which sum up to one. ${ }^{20}$

19 In the literature (e.g., Rose et al. 1998), monetary transfers have been categorized into outcomebased, allocation-based, and process-based rules. The names refer to the main motivation for a transfer rule. For instance, outcome-based rules are earmarked to generate a particular outcome and hence the surplus from cooperation is shared in some way (see the subsequent footnote). In contrast, allocation-based rules focus on the initial allocation as this is for instance the case for the initial allocation of emission permits. Allocation-based rules are considered in Altamirano-Cabrera and Finus (2006) with the STACO model; process-based rules are analyzed in Bosello et al. (2003) with the RICE-FEEM model.

20 Let $S$ denote an arbitrary coalition, $S^{N}$ the singleton coalition structure corresponding to the Nash equilibrium, and $\pi_{i}(S)$ the payoff of country $i$ without transfers if coalition $S$ forms, then the payoff of a coalition member $i \in S$ with transfer, $\pi_{i}^{T}(S)$, is given by $\pi_{i}^{T}(S)=\pi_{i}\left(S^{N}\right)+$ 
Among the many possible criteria according to which weights can be derived, I consider six schemes in Table 3 which are defined in the legend of this table. ${ }^{21}$ The first two schemes may be called pragmatic (GDP and Emissions) whereas schemes 3 to 6 can be linked to some notion of equity (Equal Sharing, Ability to Pay, Inverse Emissions, and Population). The pragmatic schemes more or less preserve the status quo and therefore have also been called sovereignty rules. ${ }^{22}$ They favor industrialized countries with high current emissions and GDP. "Equal Sharing" simply splits the cooperative pie equally. "Ability to Pay" assumes weights inverse to the GDP/Population ratio. Thus, international pollution control serves as a vehicle of income redistribution. This scheme gives much weight to highly populated and/or poor regions. "Inverse emissions" appeals to the principle of historical responsibility for climate change and "Population" is based on the principle of "one man one vote." Both schemes also favor developing countries and countries in transition as they have relatively low current emissions and a large population. The Nash Equilibrium and the Global Optimum are listed in Table 3 as benchmarks for the evaluation of the success of the various transfer schemes. In the case of multiple equilibria (as this is the case for the transfer scheme "Inverse Emissions"), the average payoff over all equilibria has been computed, which is the number besides the bracket in Table 3 .

From Table 3 it is evident that the pragmatic schemes perform better (in terms of generating stable coalitions) than the morally motivated transfer schemes. Moreover, only for the pragmatic schemes a stable coalition emerges including industrialized and non-industrialized regions. ${ }^{23}$ Additionally, we may recall from Table 2 that without transfers there is no stable coalition in this model for the base assumptions. However, also with transfers stable coalitions are relatively small and fall short of the global optimum. This leads to two conclusions.

First, transfers are important to balance asymmetries and can improve upon the success of cooperation. However, the fact that the grand coalition is not stable demonstrates that they cannot completely offset free-rider incentives. Hence, the establishment of international funds, like the Global Environmental Facility, in order to provide poorer countries with incentives to participate in IEAs (as this is the case for the Convention on Biological Diversity, the Montreal Protocol and the Kyoto Protocol) are important steps for successful international environmental cooperation.

Second, successful cooperation requires participation of industrialized and nonindustrialized regions, which I call mixed membership. This can only be achieved with moderate transfers, which take into account the fundamental interests of all actors in

$\lambda_{i}\left[\sum_{j \in S} \pi_{j}(S)-\sum_{j \in S} \pi_{j}\left(S^{N}\right)\right]$, where the surplus is the term in brackets, $\lambda_{i} \geq 0 \forall i \in S$ and $\sum_{i \in S} \lambda_{i}=1$.

21 For a more detailed description see Altamirano-Cabrera and Finus (2006) and Weikard et al. (2006).

22 In the context of allocation-based rules, the scheme "Emissions" would correspond to "grandfathering."

23 For allocation-based rules, as considered in Altamirano-Cabrera and Finus (2006) in the STACO model, results are even more pronounced. Only for pragmatic rules stable coalitions exist; no coalition is stable under any morally motivated rule considered in this paper. 
climate change. The morally motivated transfer schemes would imply large transfers between industrialized and non-industrialized regions. Hence, no coalition of mixed membership is stable. This is different for the pragmatic transfer scheme in this example. For instance, the first transfer rule GDP allows for a stable coalition between EU-15 and China. Though China receives transfers in this coalition from EU-15, which are large enough to provide China with an incentive for cooperation, they are small enough to make this coalition also attractive for EU-15. It is important to note that this conclusion depends crucially on the assumption that only material payoffs are part of countries' objective function. Different conclusions could be reached in a model with non-material payoffs in which for instance a large redistribution of wealth or development aid generates not only payoffs for developing but also for industrialized countries (see Section 4.5).

It is also worthwhile mentioning that I have only considered transfers within a coalition. The assumption implies that an outsider joining the coalition would automatically participate in the transfer schemes considered above. However, the assumption does not include at least two other interesting policy options.

The first option, though it may sound curious, is that an outsider pays another outsider for taking on more climate responsibility by joining the agreement. If the payment covers the additional abatement cost of the payee and provides the payer with a benefit in excess of his payment, this could be a viable option. For instance, this could mean that the United States, despite of not being and not becoming a member of the Kyoto Protocol, could finance membership of China or India in order to join this treaty. In the CWS model of the CGE type considered in Carraro et al. (2006) it is shown that such a strategy can work, implying a Pareto-improvement to all countries.

The second option is suggested by the current architecture of the Kyoto Protocol. The clean development mechanism (CDM) allows Annex-B-countries (i.e., mainly industrialized countries which accepted emission ceilings) to replace their own abatement activities by financing abatement activities in Non-Annex-B-countries (i.e., mainly developing countries without emission ceilings). Whether the CDM increases participation and the success of this protocol is at least from a pure game theoretic point of view not easy to predict. The reason is that in the absence of any strategic effects, CDM raises not only the welfare of signatories but also of non-signatories. If the latter effect is stronger, leaving the coalition becomes more attractive and CDM could have adverse effects. Therefore, it would certainly be interesting to evaluate these effects in an empirical climate model.

\subsubsection{Uniform Emission Reduction Quotas}

Until now, an efficient allocation of abatement within the coalition has been assumed. However, in reality, in most IEAs neither is the coalitional abatement level optimal nor is its allocation cost-effective. Typically, the coalitional abatement is below optimal levels ${ }^{24}$ and abatement duties are specified as uniform emission reduction

24 This conclusion is supported for instance by empirical studies on the Montreal Protocol (Murdoch and Sandler, 1997b), the Helsinki Protocol (Murdoch and Sandler, 1997a), the Oslo Protocol (Finus and Tjøtta, 2003), or the Kyoto Protocol (Böhringer and Vogt, 2004). 
Table 4. The role of emission reduction quotas and bargaining: Stable coalitions without trading*

\begin{tabular}{lccc}
\hline Agreement design & Coalition members & $\begin{array}{c}\text { Global abatement } \\
\text { \% of BAU }\end{array}$ & $\begin{array}{c}\text { Global welfare } \\
\text { bln US\$ }\end{array}$ \\
\hline Global optimum & Grand coalition & 21.4 & 6,031 \\
(1) Efficient Design & - & 4.6 & 1,960 \\
(2) Common Quota & India, ROW & 5.0 & 2,100 \\
(3) Median Quota & India, ROW & 5.0 & 2,103 \\
$\quad$ Proposal & India, ROW & 4.8 & \\
(4) Lowest Quota & EU-15, China, & 6.8 & 2,088 \\
$\quad$ Proposal & India, ROW & & $2,725\}(2,407)$ \\
Nash Equilibrium & Singleton coalition & 4.6 & 1,960 \\
& structure & & \\
\hline
\end{tabular}

*Agreement Design (1)-(4) as defined in Section 3.2.4. \# = no stable coalition. Global Abatement and Global Welfare as defined in Table 2.

quotas. ${ }^{25}$ In order to accommodate this observation and to provide a rationale for it, I compare the "Efficient Design" with three alternative treaty designs which are called "Common Quota," "Median Quota Proposal," and "Lowest Quota Proposal" in Table 4. ${ }^{26}$ (Again, the Nash Equilibrium and the Global Optimum are listed in Table 4 as benchmarks and in the case of multiple equilibria average welfare is displayed as in Table 3). Common Quota departs from the base assumptions (which are again the starting point for considering modifications) in one respect: coalitional abatement is chosen optimally, but not cost-effectively. That is, it is assumed that the coalition maximizes the aggregate payoff to this coalition as before but with the constraint that all members have to reduce their emissions by the same percentage from their non-cooperative levels (i.e., emission reduction quota). Median and Lowest Quota Proposal depart from the base assumptions in an additional respect. The coalitional abatement level is not chosen optimally - it is not derived from joint but from individual welfare maximization. That is, each member makes a proposal for coalitional abatement that is optimal from its point of view, assuming that this is implemented in the form of a uniform emission reduction quota. If they agree on the median proposal, this corresponds to majority voting; if they agree on the lowest proposal, this corresponds to unanimity voting.

25 The list of examples is long and includes the Helsinki Protocol, which suggested a 30 percent reduction of sulfur emissions from 1980 levels by 1993. Moreover, the "Protocol Concerning the Control of Emissions of Nitrogen Oxides or Their Transboundary Fluxes" signed in Sofia in 1988 called on countries to uniformly freeze their emissions at 1987 levels by 1995 and the "Protocol Concerning the Control of Emissions of Volatile Organic Compounds or Their Fluxes" signed in Geneva in 1991 required parties to reduce 1988 emissions by 30 percent by 1999 .

26 The idea of uniform emission reduction quotas goes back to Endres (1997) and Eyckmans (1999). 
Since the Efficient Design corresponds to the base assumptions we know from above that no coalition is stable. For the design Common Quota and Median Quota Proposal one coalition between India and ROW is stable. This coalition is also stable for the design Lowest Quota Proposal but global welfare is lower. However, there is an additional stable coalition of four regions with higher global welfare. The average global welfare for the Lowest Quota Proposal is higher than for the other two quota designs.

It is evident that in a given coalition and abstracting from stability considerations, any departure from the Efficient Design implies a global welfare loss. This welfare loss is particularly big in large coalitions and is particularly pronounced for the Lowest Quota Proposal. ${ }^{27}$ However, including stability considerations, no coalition is stable for the Efficient Design without transfers. This is because this design implies an asymmetric distribution of abatement allocation associated with an asymmetric distribution of the gains from cooperation. Moreover, it means that an ambitious coalitional abatement level is implemented. In contrast, the quota designs lead to a more symmetric distribution of the gains from cooperation and implement more modest coalition abatement targets which is pronounced particularly for the Lowest Quota Proposal. In the example, the departure from cost-effectiveness and ambitious abatement targets is rewarded. Because of strong free-rider incentives, the Lowest Quota Proposal is the most successful design. ${ }^{28}$

This conclusion is also confirmed if we allow for the possibility that quotas can be traded within a coalition as displayed in Table 5 . Since trading constitutes a win-winsituation for all coalition members, coalitional members' payoffs increase and hence also global welfare for a given coalition structure. ${ }^{29}$ Hence, the difference between the Efficient Design and the three quota designs is only due to the "modesty effect," i.e., lower coalitional abatement levels in a given coalition since trading leads to cost-effectiveness. ${ }^{30}$

The Pareto-improving effect of trading has two implications. First, it is less attractive to leave a coalition. That is, internal stability is strengthened. Hence, all coalitions that have been internally stable without trading are also internally stable with trading and may be some additional coalitions. This is why for instance the coalition between India and ROW which is stable in Table 4 is also internally stable in Table 5. Second, it becomes more attractive for outsiders to join a coalition. That is, external stability is weakened. This is why for instance the coalition between India and ROW is no longer externally

27 For instance for the grand coalition, the Efficient Design implies a global welfare of 6,031 bln US\$ (as displayed in Table 4) whereas for the designs Common Quota, Median Quota Proposal, and Lowest Quota Proposal we find 4589, 4565, and 3212 bln US\$ (not displayed in Table 4), respectively. See Altamirano-Cabrera et al. (2008), Table 1.

28 A similar conclusion is reached in a compliance model in Endres and Finus (2002) and Finus and Rundshagen (1998).

29 For the grand coalition (as reported in the previous footnote), global welfare for the designs Common Quota, Median Quota Proposal, and Lowest Quota Proposal is now given by 5547, 5703, and 3345 bln US\$ (not displayed in Table 5), respectively. See Altamirano-Cabrera et al. (2008), Table 1.

30 That modesty can pay is also confirmed in theoretical models with symmetric players. In a membership model this is shown in Finus (2004) and in a compliance model in Barrett (2002). 
Table 5. The role of emission quotas and bargaining: Stable coalitions with trading*

\begin{tabular}{|c|c|c|c|}
\hline Agreement design & Coalition members & $\begin{array}{l}\text { Global abatement } \\
\% \text { of BAU }\end{array}$ & $\begin{array}{l}\text { Global welfare } \\
\text { bln US\$ }\end{array}$ \\
\hline Global optimum & Grand coalition & 21.4 & 6,031 \\
\hline (1) Efficient Design & - & 4.6 & 1,960 \\
\hline \multirow[t]{2}{*}{ (2) Common Quota } & India, $\mathrm{ROW}^{I}$ & 5.0 & 2,104 \\
\hline & $\begin{array}{l}\text { Japan, EU-15, China, } \\
\text { India }\end{array}$ & 7,3 & 2,982 \\
\hline (3) Median Quota & India, ROW ${ }^{I}$ & 5.0 & 2,104 \\
\hline \multirow[t]{4}{*}{ Proposal } & Japan, India, ROW & 5.5 & \\
\hline & Japan, EU-15, China, & 7.3 & \multirow{2}{*}{$(3,008)$} \\
\hline & USA Janan China India & & \\
\hline & $\begin{array}{l}\text { USA, EU-15, China, } \\
\text { India }\end{array}$ & $\begin{array}{l}0.0 \\
9.0\end{array}$ & 3,492 \\
\hline (4) Lowest Quota & India, $\mathrm{ROW}^{I}$ & 4.8 & 2,088 \\
\hline \multirow[t]{3}{*}{ Proposal } & $\begin{array}{l}\text { EU-15, China, India, } \\
\text { ROW }^{I}\end{array}$ & 6.8 & 2,811 \\
\hline & $\begin{array}{c}\text { Japan, EU-15, China, } \\
\text { India, ROW }\end{array}$ & 7.5 & \multirow{2}{*}{$\left.\begin{array}{l}3,050 \\
3,350\end{array}\right\}(3,200)$} \\
\hline & $\begin{array}{l}\text { USA, Japan, EU-15, } \\
\text { China, India }\end{array}$ & 8.4 & \\
\hline Nash Equilibrium & $\begin{array}{l}\text { Singleton coalition } \\
\text { structure }\end{array}$ & 4.6 & 1,960 \\
\hline
\end{tabular}

*Agreement Design (1)-(4) as defined in Section 3.2.4. \# = no stable coalition; I = only internally stable coalition. Global Abatement and Global Welfare as defined in Table 2.

stable with trading. However, this external instability of small coalitions is rewarded by larger stable coalitions in this example. For all three quota designs, average global welfare of stable coalitions with trading is higher than without trading. The ranking within the three quota designs according to average global welfare remains the same: the highest average global welfare is obtained for the design Lowest Quota Proposal, followed by Median Quota Proposal and then Common Quota.

From Tables 4 and 5 the following three policy conclusions emerge, taking in consideration that IEAs have to operate in a second-best world, i.e., participants face free-rider incentives but no third party can enforce a treaty. First, in the absence of transfers, there is a rationale for implementing uniform emission reduction quotas. Despite being not cost-effective, quota agreements may be more successful as the gains from cooperation are more equally shared. Second, the pressure for consensus treaties is not always an obstacle for successful cooperation. If a sufficiently high participation makes up for the negative effect of modest abatement targets, the overall effect may well be positive. 
This conclusion ("better a bird in hand than two in the bushes") gains momentum when considering (by taking a wider perspective) that many IEAs have been established first with modest abatement targets, as for instance the Montreal Protocol on the Reduction of CFCs. Subsequently, amendment protocols followed which gradually tightened abatement targets and broadened the base of regulated pollutants. ${ }^{31}$ Third, emission trading, as for instance established for the first time within the Kyoto Protocol, can increase participation and the success of a treaty. This stresses the importance of this instrument not only for cost-effectiveness but also for the incentive of participation in IEAs.

\section{POSSIBLE EXTENSIONS}

\subsection{Introduction}

Some of the results in the previous section have a positive dimension. With positive dimension I mean that these results help to rationalize apparently second- or third-best designs of actual IEAs. Examples include the following conclusions: (a) uniform may be superior to differentiated and cost-effective emission reductions (Tables 4 and 5); (b) trading of uniform emission reduction quotas has a positive effect on participation and efficacy of IEAs (Table 5); (c) modest may be superior to ambitious emission reductions (Tables 4 and 5). Of course, at the same time, these insights provide also some normative guidance for the pragmatic design of future IEAs.

However, some results seem to have an exclusive normative dimension. For instance, we concluded that (d) multiple are superior to single agreements (Table 2) and (e) exclusive is superior to open membership (Table 2). Clearly, all current IEAs are single agreements as there is for instance only one Montreal Protocol and one Kyoto Protocol. Of course, one may argue that recent developments seem to indicate that a group of countries around the United States may set up an additional climate treaty. However, without any doubt, all current environmental agreements of global scale do not restrict accession and therefore adhere to the principle of open membership. Moreover, membership in Tables 2-5 under various institutional assumptions is neither in line with participation in the current Kyoto Protocol nor with the expectations of probably most experts and observers on climate change. For instance, the "current Kyoto coalition," corresponding roughly to a coalition of Japan, European Union (EU-15), Other OECD countries (O-OECD), Central and Eastern European Countries (EE) and the Former Soviet Union (FSU) according to the regional classification in the STACO model is not stable under any of the assumptions considered here. In contrast, depending on the assumptions, a coalition of the Former Soviet Union (FSU), Brazil, and ROW may form a stable coalition (e.g., Table 2).

A partial answer to resolve this puzzle could be to point out that is very likely that the Kyoto coalition will indeed turn out to be unstable as predictions suggest that many

31 See for instance the Appendix in Finus (2007). 
participants will not be able to fulfill their abatement obligations in the first commitment period 2008-2012. It may also be pointed out that politicians are not completely rational, pursue other goals than maximizing the welfare of its citizens or simply do not know for instance that exclusive is superior to open membership. After all, economists have put forward numerous normative policy recommendations - not only in environmental economics - that have not fallen on fertile ground. It is certainly beyond the scope of this paper to provide a complete solution to this puzzle. However, it is clear that a stylized model can only capture a small amount of the diverse factors that play a role in the actual setting under which the Kyoto Protocol is operating. Some of these factors may not even be known. Moreover, even from a purely theoretical point of view, it is obvious that some aspects of coalition formation have been neglected in the previous analysis. In the following, with reference to Table 1, I will discuss some aspects which I believe are the most prompting one to be considered in future research. ${ }^{32}$ It will become apparent some of the issues have already been treated, though some under very specific assumptions with no general and clear-cut conclusions.

\subsection{Sequential Participation Decisions}

The base assumption implies that all countries decide simultaneously upon their participation. However, casual empirical evidence suggests that signature and ratification of environmental treaties occur sequentially. Typically, some initiators kick off the negotiation process, a core group of countries participate in an agreement and other countries may follow suite at a later stage. ${ }^{33}$

However, modeling coalition formation as a sequential process introduces a couple of conceptual problems that are difficult to solve. For instance, in the case of heterogeneous countries, the sequence in which countries decide upon their participation has to be endogenized. In a model with a dynamic payoff structure, which means in particular that the payoff at time $t$ depends on accumulated emissions (i.e., stock of emissions or concentration in the context of greenhouse gases), the number of strategic options increases dramatically. As the incentives of the game change over time, neither constant abatement strategies nor participation strategies can be optimal. Whereas dynamic abatement strategies are considered in CGE models, a truly dynamic coalition model also requires considering dynamic participation strategies. That is, optimal abatement levels as well as

32 I will not cover at least one issue that I believe is also important in the context of IEAs. This is the link between cooperation on environmental issues and R\&D. The analysis of the link between environmental and some other policy issues in order to improve the prospects of IEAs has been initiated by Folmer et al. (1993) and Folmer and van Mouche (1994) in the context of compliance models. Later contributions analyzed issue linkage also in the context of membership models as for instance Barrett (1997) and Carraro and Siniscalco (1997). Recently, this topic has gained new momentum with the focus on how the design of an IEA affects endogenous technological progress and how this affects the success of an IEA. See for instance Buonanno et al. (2003), Fischer et al. (2003), Golombek and Hoel (2005), and Kverndokk and Rosendahl (2007).

33 The evolutionary development of some IEAs is reported for instance in the appendix in Finus (2007). 
optimal participation strategies have to be determined at each point in time in a recursive way, anticipating the implication in the future of decisions today.

Until now only a few preliminary results are available with limited policy-relevance. The reason is that all results have been derived from highly stylized models with symmetric countries ${ }^{34}$ and many other very specific assumptions.

The simplest extension assumes a sequential coalition formation process according to the sequentially more unanimity game of Bloch (1995) as considered for instance in Finus and Rundshagen (2006b) and Ray and Vohra (2001). In this game, membership is exclusive and multiple coalitions may form. Once a coalition has formed by unanimous voting, membership cannot be revised.

From these papers it appears that time introduces an additional strategic component: countries have an incentive to commit to no or low cooperation in the early stage of the formation process, thereby increasing the pressure on other countries for cooperation. Moreover, due to strategic considerations, full cooperation may not be possible; the equilibrium coalition structure may not even be Pareto-optimal. ${ }^{35}$ Surely, this is hardly a surprising result and not so much different from what has been obtained with simpler models assuming a simultaneous participation process. Moreover, contrary to reality, the initiators are not those countries that establish an agreement but those which free-ride.

A more interesting analysis is conducted in Rubio and Ulph $(2002,2007)$. Both papers consider in the base model of an open membership single coalition game a stock pollutant and the decision about membership over time. Models are simple as countries have only a dichotomous choice between no abatement and abatement. In the first paper, only two periods are considered. In line with real world observations, the authors show that participation rises in the second period compared to the first period. However, this seems to be an artificial result, as the authors admit, because the finite time horizon introduces an end point bias. In the last period (here the second period), no environmental damages in subsequent periods have to be considered. Hence, optimal abatement is low and participation is associated with low abatement costs. This qualification is confirmed by the infinite horizon version in the second paper. Here the authors find that participation is a non-increasing function of time.

Hence, it appears that only two policy-relevant conclusions can be derived from these papers. First, under reasonable assumptions the equilibrium stock of emissions increases over time, approaching some steady state. However, this is already known from empirical climate models like RICE (Nordhaus and Yang, 1996) and WIAGEM (Kempfert, 2005) though the particular focus on partial instead of full cooperation is new. Second, the authors confirm a conclusion for the assumption of efficient abatement within a coalition that not only in a static but also in a dynamic setting the success of coalition formation is

34 Symmetric players means that all players have the same payoff function. Sometimes this is also called $e x$-ante symmetric players as $e x$-post signatories and non-signatories receive different payoffs since they chose different abatement levels.

35 A Pareto-optimal coalition structure is a coalition structure such that there is no other coalition structure where at least one player would be better off but no player would be worse off. 
negatively related to the level of environmental damages. ${ }^{36}$ However, despite these critical remarks, no doubt, the research direction kicked-off by Rubio and Ulph $(2002,2007)$ is an important and promising one if it is combined for instance with some ingredients I mention below. This may allow deriving more realistic conclusions.

\subsection{Sequential Abatement Decisions}

The standard assumption implies that the coalition, acting as a single player, and the outsiders, acting as singletons, simultaneously chose their optimal abatement policy. An alternative assumption, introduced by Barrett (1994) and further developed by Diamantoudi and Sartzetakis (2006) and Rubio and Ulph (2006), is that this happens sequentially. They assume that the coalition acts as a Stackelberg leader, taking the (aggregate) best response of outsiders in consideration, when choosing its abatement. This informational advantage can reduce the degree of leakage and leads to larger and more successful coalitions. ${ }^{37}$

Until now, this result has only been established for the assumption of symmetric players and three specific payoff functions. ${ }^{38}$ Nevertheless, it seems suggestive that this result should hold more generally. From a theoretical point of view, however, there are two problems with this alternative assumption. First, in a model with symmetric players and/or payoff function comprising only cost and benefits from abatement, the informational asymmetry does not follow from the model itself and requires some exogenous motivation. Second, in the special context of coalition formation, the question arises why potential coalition members should assume that they loose their informational advantage once they leave the coalition. From an applied point of view, the result is more interesting, suggesting that successful cooperation should take in consideration the strategic reaction of outsiders.

\subsection{Subjective Payoffs}

The STACO model, like other climate models, groups countries into regions for tractability. Even though in climate negotiations some countries coordinate their strategies, like the European Union or the group of G77 countries, after all, countries take sovereign decision when it comes to accepting final abatement targets and signing and ratifying a treaty. This introduces a bias in the incentive structure. Anything else being equal, we should expect that this aggregation into regions overestimates the success of cooperation derived from climate models. This qualification calls for a model with more

36 This result is summarized and explained in Finus (2003a) for the static setting. See in particular Result 2 in Section 3.3.2.

37 Leakage effect means that non-signatories lower their abatement as a reaction to higher abatement of signatories. For instance, if the members of a climate agreement reduce their energy demand, energy prices drop, inducing higher demand by outsiders.

38 For an overview see Finus (2003a), Table 3.2, p. 108. 
disaggregated data. However, apart from the fact that more disaggregate data is currently not available, such an extension would require a substantial amount of additional computer resources. ${ }^{39}$

Moreover, as far as I am aware, all climate models derive the parameters of their abatement cost functions and benefit functions from some "scientific sources." Apart from the difficulty to monetize environmental damages in general, these estimates try to evaluate "objective" damages. For instance, most climate models assume high environmental damages in developing countries summarized in the region ROW. From a normative view point this may not be seen as a problem. However for a positive analysis, this may introduce some bias. There are some reasons to believe that the subjective perception of damage costs of ROW is substantially lower than those assumed in most climate models, overestimating the interest of this heterogeneous region for cooperation. For instance, as these countries typically prioritize economic development over environmental issues, it can be expected that environmental damages receive a low weight.

One possibility to improve upon estimates for a positive analysis could be to use data from contingent valuation studies to calibrate climate models. For instance, Böhringer and Vogt (2004) suggest, based on a survey of various studies, that the willingness to pay for global greenhouse gases is even in industrialized countries rather low. However, it is also evident from their survey that the current data basis is very small — only few country studies are currently available.

\subsection{Political Process}

The base model assumed that abatement within a coalition is derived from joined welfare maximization of coalition members. As already pointed out, there are at least four problems with this assumption. First, it is not consistent with the notion of non-cooperative game theory. Second, it certainly overestimates the sense of cooperation among governments, even though they are willing to take joint action. Third, it presumes infinitely living decision makers who take all future implications of their decisions today into considerations. Fourth, already casual empirical evidence suggests that this simply does not reflect what is really happening in international negotiations: coalitional abatement is neither optimal nor is its allocation cost-effective. Certainly, one improvement to accommodate this critique was the previous assumption of a bargaining process over uniform emission reduction quotas. However, this can only be seen as a first step.

First, the set of bargaining options was restricted (e.g., Median Quota and Lowest Quota Proposal), may not apply to all situations of international environmental negotiations and the choice of the negotiation regime was not endogenized. Moreover, in the case of transfers, though several options were considered, the choice of the transfers scheme (i.e., the choice of weights) was not endogenized. Second, and most important,

39 In the context of only 12 world regions, there are already more than four billion different coalition structures in the case of multiple coalitions. This number increases exponentially with the number of regions. 
the political process that defines the positions of governments in international negotiations has not been considered explicitly (e.g., Michaelowa, 1998). This shortcoming is shared by all coalition models as far as I am aware and was noted already by Carraro and Siniscalco (1998). Hence, one possibility to improve upon the predictive power of coalition models could be to include public choice aspects, like interest groups, governmental decision processes, and parliamentary voting. Moreover, overlapping generation models with short-lived agents could be constructed in order to capture the myopic view typically prevailing in politics. However, apart from increasing the complexity of models, it should be expected that it will be difficult to identify and quantify political variables for an empirical analysis. ${ }^{40}$

\subsection{Non-material Payoffs}

The base assumptions imply that decisions about participation and abatement are solely based on costs and benefits from abatement (i.e., material payoffs). From a normative (e.g., in the sense of welfare economics) as well as from a positive perspective (e.g., in the sense of public choice) one may argue that this view is too narrow. From a normative perspective one may argue that it is exactly for this reason why cooperation proves so difficult in reality and why game theoretic models confirm this pessimistic view. From a positive perspective there may be the conjecture that also aspects like reputation or ethical considerations of fairness play some role when negotiating an IEA and deciding on participation and compliance. Moreover, one may presume that these aspects are at least partially responsible for explaining some of the success stories of IEAs, like for instance the frequently cited Montreal Protocol.

Though the normative perspective is an extremely relevant and important issue of non-material payoffs, scientifically it is of limited interest. Even without resorting to non-material payoffs, full cooperation could easily be achieved in theory if all actors would not only consider their own payoff but also the benefits occurring to others from their abatement when (a) choosing their abatement level, and (b) deciding whether to join or leave an IEA. Then the grand coalition, implementing the social optimum, would be the unique stable outcome. Even in a richer model, the normative dimension of the problem would call for the complete internalization of all transboundary externalities across all actors. That is, all actors care also for the well-being of others, regardless how this is defined. A more interesting issue is certainly the question: How is it possible to change the preference of actors so that they consider externalities they impose on others? This question is related to the role and formation of norms as well as reputation and the institutions that help in shaping them. Unfortunately, as far as I am aware, no such research in the context of IEAs has been conducted in environmental economics.

40 As far as I am aware, only Bucholz et al. (2005) and Altamirano-Cabrera (2007), Chapters 7 and 8, consider public choice aspects in transboundary pollution. However, Bucholz et al. (2005) is a highly stylized model with only two symmetric players. Hence, the problem of coalition formation does not arise. The work of Altamirano-Cabrera (2007) is a very promising approach as he considers public choice aspects and coalition formation in the STACO-model. However, the analysis must be judged as preliminary as it appears to be flawed by some inconsistent assumptions. 
The positive perspective is scientifically interesting but also difficult. The main question that arises is to which extent and in which sense do reputational and ethical aspects guide the behavior of actors? However to the best of my knowledge, this question has not really been addressed yet. ${ }^{41}$ On the one hand, there is a couple of theoretical papers which have analyzed how non-material payoffs influence the success if IEAs. On the other hand, there is one empirical paper that conducted a questionnaire among employees in governmental and international institutions involved in climate change on the importance they attach to different notions of equity. Though this survey is important, by its nature we should expect a bias between stated preferences and those underlying actual negotiations. ${ }^{42}$ In the following, I briefly review these papers.

Jeppesen and Andersen (1998) and Hoel and Schneider (1997) add a term to the "classical payoff function," which the former call a "non-material payoff," representing the idea of fairness, and the latter "non-environmental cost of breaking the agreement." They assume that all countries' (symmetric) payoffs comprise benefit minus cost from abatement (material payoff) but that non-participants receive additionally disutility from being outsiders (non-material payoff) where disutility increases with the number of countries participating in an IEA. Not surprisingly, both papers find that the higher the disutility of being an outsider, the larger will be the equilibrium coalition. At least technically, this result seems obvious, as it follows almost by assumption. ${ }^{43}$

Lange and Vogt (2003) assume that the utility of a country is the weighted sum of the absolute material payoff function and the relative material payoff function. The relative material payoff function obtains its maximum for the average payoff of all countries. Any deviation from the arithmetic mean is interpreted as inequality and counts as disutility. For the assumption of symmetric countries, they show that if relative payoffs receive a sufficiently high weight compared to absolute payoffs, the grand coalition emerges as an equilibrium coalition. Unfortunately, they do not analyze which equilibrium emerges if relative payoffs receive some weight but not sufficiently much in order to stabilize the grand coalition. Instead, they run simulations for a particular benefit and cost function assuming that there are 12 countries in total of which half care exclusively about absolute payoffs (A-countries) and half of them care exclusively about relative payoffs

41 There are only few empirical studies on the behavior of countries in the context of IEAs. In the context of climate change, see Böhringer and Vogt (2004); in context of sulfur emissions, see Murdoch and Sandler (1997a) and Finus and Tjøtta (2003) and in the context of CFCs, see Murdoch and Sandler (1997b) and Swanson and Mason (2003). However, none of these papers include ethical aspects.

42 We should expect that negotiators state a higher preference for equity than their actual perception. In a survey equity comes at no cost whereas in actual negotiations equity would be associated with lower material payoffs for industrialized countries (as this would imply for instance higher monetary, technological or in-kind transfers from industrialized to developing countries). Such a bias is well-known for instance from contingent valuation studies. See for instance Hanley et al. (1997).

43 A non-obvious result in Hoel and Schneider (1997) is derived from an extension which considers the role of transfers paid by members to non-members for increasing their abatement efforts. However, their conclusion that transfers may have a negative impact on cooperation is flawed by their conceptual setting as I argue in Finus (2003a), Section 3.3.4. 
(B-countries). Their example illustrates that there can be multiple equilibria, comprising a different mix of A- and B-countries. However, given that simulations are only based on one parameter set, no general conclusions can be drawn from this example.

A similar approach is pursued in Peters and Schuler (2006). However, there are two differences. First, disutility does not stem from payoff differences but from abatement differences. This assumption has some connection to the assumption of uniform emission quotas discussed in Section 3.2.4. However, whereas in Section 3.2.4 the preference for uniformity was simply assumed, in Peter and Schuler (2006) it is at least part of the payoff function, though still exogenous. This explicit statement may be judged as an advantage as it increases the transparency of assumptions. Second, inequality is not simply measured as the deviation from the mean but by the variance. This corresponds to a wider definition of inequality. Even if a country chooses an average abatement level, this may be associated with negative utility as long as this average deviates from the maximum and minimum abatement level. Basically, Peters and Schuler confirm Lange and Vogt (2003) that if inequality aversion plays a sufficiently important role in countries payoff function, the grand coalition will emerge as a stable agreement. If inequality aversion is below this threshold, they show that multiple equilibria may emerge that range from no cooperation to partial cooperation with almost full participation. Moreover, they demonstrate that no correlation between inequality aversion and the size of coalitions can be established. ${ }^{44}$

Apart from the difficulty to reach general conclusions about the role of inequality aversion in the models by Lange and Vogt (2003) and Peters and Schuler (2006), there are at least two more problems. First, there is no empirical evidence that would back either one of the two different measures of inequality aversion or suggest another one. For instance, in the context of global warming, fairness has been associated with the call for different responsibilities. This may be in line with similar abatement obligations within the group of developed countries, countries in transition and developing countries but certainly not across groups. Of course, the models assume symmetric countries, but even in such a setting one could imagine that the herd instinct as it has been called by Peters and Schuler (2006) only prevails within the group of coalition members and non-members but not among both groups. Second, neither of the two papers offers conclusions with respect to global welfare and global abatement. Though in a symmetric setting one may conjecture that there is a correlation between the size of stable coalitions and global welfare as well as abatement, this has to be analyzed.

Finally, I turn to the questionnaire by Lange et al. (2007). They contacted 1695 people (of which 230 responded) working for governmental bodies and international organizations involved in climate change policy. Questions about the importance of six equity rules for short- and long-term climate policy were put forward. Responses served as an input into various econometric tests. They find that equity criteria are generally considered as important by the respondents, though this was more important for respondents from developing countries and countries in transition than for those from

44 A similar inconclusive result is obtained in Lange (2006). Though this model is very rich in terms of the policy setting, the analysis is incomplete as it does not consider external stability. 
industrialized countries. The polluter pays principle (i.e., equal ratio between abatement costs and emissions) and the poor losers principle (exemptions from abatement duties due to very low GDP) are the most widely accepted equity principles. Moreover and most important, there is a strong correlation between the importance attached to a particular equity criteria and the economic impact associated with it. That is, respondents favored those equity criteria that are associated with relatively low abatement obligations for their countries of origin.

Overall, this seems to suggest that equity criteria are just disguised means in the political arena in order to push through strategic economic goals in negotiations. Whether this negative conclusion holds generally will have to be investigated in future research. In particular, one may expect that there is a bias between stated and actual preferences. Moreover, stated preference for equity criterion of respondents may differ from those which actually entered into agreements. Therefore, it would be interesting to investigate not only stated but revealed preferences by investigating the correlation between the design of actual IEAs and their implied equity principle. For instance, the equity criteria "sovereignty rule" in Lange et al. (2007) seems to have played an important role in the past as it is defined as equal percentage reduction of current emissions, which I referred to as uniform emission reduction quotas in Section 3.2.4. See in particular footnote 25 .

\subsection{Uncertainty}

The base assumptions imply that all payoff functions are known with certainty. This is surely a heroic assumption for several reasons. For instance, the impacts of climate change are highly uncertain. This concerns the impact of greenhouse gas concentration on the climate, the impact of the climate on the environment and the relation between changes of environmental quality and its evaluation by people. In particular, the large time lag between emissions today and future environmental damages due to the accumulation of emissions makes estimates difficult. Moreover, large discontinuities are expected that could characterize damages (e.g., threshold effects or tipping points - albedo effects, methane release from tundra, stopping of the thermohaline circulation system, etc.; see e.g., Clarke and Reed (1994) and Gjerde et al. (1999)). However, also the prediction about future abatement costs are difficult as future abatement technologies, economic growth and the relation between growth and emissions are not known today. This suggests that there is uncertainty regarding the parameters of the payoff function and its exact functional form. Moreover, we may suspect that there is also asymmetric information (e.g., Caparrós et al. 2004). Though representative of countries may have some idea about their own evaluation of the climate problem and possible solutions, they face uncertainty about the perception of their neighbors.

In order to study the strategic implications of uncertainty, it is necessary to specify how agents form expectations. This requires making assumptions about the distribution of the random parameters and the functional forms. Moreover, it requires specifying whether and how uncertainty is resolved through learning. In reality, learning is usually imperfect, meaning that the true state of the world is only revealed gradually but never 
complete. Methodological, this would mean that believes are sequentially updated as more information becomes available (e.g., through Bayesian learning). However, this would lead to very complex models. Therefore, as far as I am aware, all models on uncertainty and learning assume perfect learning. That is, if information is revealed, the true state of the world is revealed to all countries. Despite this simplification, clear-cut conclusions are difficult to obtain as there are basically two opposing effects.

On the one hand, the possibility that better information will be available in the future which reduces uncertainty leads to the suggestion that abatement activities should be delayed. For instance, it may turn out that cheaper abatement options will be available in the future. Hence, current abatement activities may turn out to be unnecessarily costly. In particular, if abatement today is associated with high fixed costs, this can make it more difficult to switch to cheaper options in the future (Kolstad, 1996). On the other hand, the irreversibility of greenhouse gas accumulation calls for early action in case it turns out that climate damages are more severe than expected (Ulph, 1998). Moreover, current stricter environmental regulation may boost technological progress, making abatement cheaper in the future.

However, even in the simple models of Ulph (1998), Ulph and Ulph (1997), and Ulph and Maddison (1997) it is difficult to obtain general conclusions. These models consider only two periods with a stock externality, a fixed abatement technology, only uncertainty with respect to damages, which can only be high or low (e.g., there are only two states in the world), and two symmetric countries which may only differ in damage costs. In the case of no learning, abatement decisions are taken on expected damages. For their model assumptions, this case corresponds to the case of no uncertainty, except that the value of the certain damage parameter is replaced by its mean value. ${ }^{45}$ In the case of learning, true damages are revealed after the first period and countries can take optimal decisions.

These papers confirm that total accumulated emissions are higher in the Nash equilibrium than in the social optimum, with and without learning. They also show that the value of learning (i.e., in the form of higher global welfare) is usually positive in the social optimum, except for the special case of negatively correlated damages in which case this value is zero. This is of course not surprising since more information should lead to better decisions. More surprising are two findings.

First, only for specific payoff functions is it possible to conclude whether first period abatement levels are higher or lower with than without learning. This holds for the Nash equilibrium and the social optimum. This suggests that no general conclusions are possible whether early action is sensible. This qualification gains even more momentum when considering that countries are usually asymmetric, damage costs parameters may be distributed over a large interval and future abatement costs are also uncertain. Second, if damages are sufficiently negatively correlated in these models, the value of information can become negative in the Nash equilibrium. That is, in a strategic setting,

45 They assume - as all other models do as far I am aware - that utility is linear in payoffs, implying risk neutrality. For their payoff function the theorem of certainty equivalence holds. See footnote 49 . 
learning can be bad. The intuition is that without learning, both countries are ex-ante and ex-post symmetric and hence choose symmetric abatement levels in both periods. Though abatement is below socially optimal levels, it is conducted cost-effectively as both countries have the same abatement cost function. With learning, countries choose different abatement levels as they find out ex-post that their true damage costs differ. This implies a further departure from the social optimum.

The driving force of this negative conclusion about the value of learning in a strategic setting is also present in a simple static three country model with coalition formation in $\mathrm{Na}$ and Shin (1998). Countries have the same payoff function which differs only in the damage parameter. This parameter is uniformly distributed with the same expected value for all countries. Without learning, which they call ex-ante negotiations, no information is disclosed; neither before the first stage nor before the second stage of coalition formation. Hence, the expected payoff from forming a coalition is the same for all countries. Hence, the grand coalition is stable in their model. With full learning, which they call ex-post negotiations, the true damage parameter is revealed to all countries before the first stage. For the base assumption of joint welfare maximization of the coalition, this implies symmetric abatement levels within a coalition from which countries benefit differently due to different damages. Hence, as no transfers are assumed, the grand coalition is not stable anymore in their model. ${ }^{46}$

It is evident that the conclusion on the negative value of information needs some caution as all the models mentioned above make very specific assumptions. This is also true for the coalition models by Kolstad (2007) and Kolstad and Ulph (2006). Both papers consider the case of a positive correlation and no correlation of damage parameters between an arbitrary number of countries. Contrary to the papers above, they also find a negative value of information in the case of a positive correlation of uncertainty. However, their payoff function is very special: damages and abatement costs are linear and hence optimal abatement decisions are boundary solutions, meaning that either abatement or no abatement is optimal. Moreover, in the case of no correlation of uncertainty, it turns out in these models that the value of information may become positive. ${ }^{47}$ Such mixed evidence also holds for the case of partial learning which means that uncertainty is resolved after the first stage but before the second stage. Thus, only membership decisions have to be taken without knowing the true damage parameters. ${ }^{48}$

46 Fujita (2004) claims that this conclusion would disappear with transfers and more than three countries. However, he wrongly claims that his stability concept of the CS-core would be identical to internal and external stability as applied in $\mathrm{Na}$ and Shin (1998). Thus, results cannot be compared.

47 Also in the STACO model with uncorrelated uncertainty of abatement cost and benefit parameters (and continuous choices of abatement) it is shown in Dellink et al. (2005) that in the case of full learning the value of information can be positive in the context of coalition formation.

48 The strong dependency on assumptions is also evident from Ulph (2004). This model is in the tradition of the models of Rubio and Ulph $(2002,2007)$ on dynamic coalition formation. Despite the assumption of symmetric players and only a dichotomous choice of abatement levels (due to linear abatement and damage cost functions) a comparison of no learning and full learning has to resort to simulations with mixed evidence. 
Taken together, we may conclude that uncertainty is a very important and relevant aspect of climate change. However, our understanding what it means for the strategic interaction between countries and for the prospects of cooperation is still very basic and incomplete. The main problem is the complexity of uncertainty and learning which makes it necessary to work with very simple models which do not allow drawing general conclusions. Most models are static or consider only two periods, assume symmetric countries and consider only uncertainty of climate damages. Moreover, none of the models on coalition formation considers the possibility that countries can take actions to reduce uncertainty. For instance, apart from the possibility to invest in research and development in order to reduce scientific uncertainty, there may be the possibility that increased abatement efforts reduce the spread of uncertain damages. If decision-makers are sufficiently risk averse, this could provide an incentive for more cooperation. ${ }^{49}$

\subsection{Coordination}

The claim that IEAs have to be self-enforcing rests on the observation that there is no supranational authority with enforcement power. Though I agree with this view, this neglects at least two issues. From a positive point of view the question arises why governments resort to international law when they have disputes about the interpretation of treaties or accuse other parties for not meeting their obligations? Moreover, there are international organizations like UNEP, the World Bank, and the WTO that are involved in transboundary environmental externalities in one way or another. For instance, the WTO is involved in settling trade disputes also related to environmental standards. UNEP coordinates some environmental policies and calls for instance for increasing efforts to combat global warming. The World Bank manages some projects related to the CDM and the Global Environmental Facility. Ignoring such phenomena in models means simply that no rationale can be provided for the existence of these institutions.

From a normative point of view the question arises whether these or other international institutions, even though they cannot enforce IEAs, cannot play a constructive role as coordinators or mediators. This concerns for instance the stage of negotiation, signature, ratification, and implementation of an IEA. Also international law may at least provide some guidance of good conduct. Again, ignoring such phenomena may mean to ignore relevant instruments for increasing international cooperation in mitigating transboundary environmental problems.

Taken together, it would be important to clarify how these institutions have been evolved over time and their impact for actual treaty making. Hence, I would strongly advocate supplementing game theoretic analyses by insights from international law, institutional economics and political sciences, to name only three disciplines, respectively

49 Such an idea is pursued in Endres and Ohl $(2000,2002,2003)$. They show in a simple static prisoners' dilemma game that if agents are sufficiently risk averse and cooperation can reduce the spread of uncertainty of payoffs, partial or full cooperation can be an equilibrium. 
methods. That this can be a successful strategy shall be briefly illustrated with two examples. Though both examples remain in the domain of game theory and do not take an evolutionary perspective, they provide at least some hint how such a research strategy could look like.

In Finus and Rundshagen (2006b) it is shown that in the case of multiple stable coalitions a third party can bring about a Pareto-improvement to all countries. This third party can help to coordinate participation strategies, despite it has no enforcement power. ${ }^{50}$ Though this model is very simple, it is easy to imagine that a third party may also be successful in coordinating abatement strategies. Moreover, in richer models, coordination may be extended to many other aspects of the design of IEAs, like transfer payments, monitoring, and dispute settlement.

Another interesting aspect of coordination is analyzed in Carraro et al. (2004), Haeringer and Courtois (2005), Rubio and Casino (2005), and Rutz (2002), Chapter 6. Though these models differ in detail, they all consider the effect of a minimum participation clause. The motivation derives from the fact that almost all IEAs concluded in the past operate under such a clause. For instance, Rutz (2002) reports that only 2 out of 122 IEAs that he considered had no such rule. In juridical terms, a minimum participation clause specifies the number of instruments of ratification, acceptance, approval or accession that have to be deposited before a treaty enters into force. In the game theoretic and economic jargon, all instruments simply mean becoming a signatory and "enters into force" means that only from now onwards agreed obligations are considered as binding for all members to an IEA. For instance, the Kyoto Protocol required a double-trigger before it entered into force. First, at least 55 parties had to ratify the treaty by their national parliaments. Second, parties had to account for at least $55 \%$ of the total 1990 $\mathrm{CO}_{2}$-emissions of all Annex-B parties.

All papers mentioned above analyze this feature in the base model with symmetric countries in a two step procedure. First, they show that a stable coalition is small without this clause. This is because if the number of signatories increases sufficiently, it becomes attractive to leave a coalition, given that all other countries remain in the coalition. More precisely, if we let $n$ denote the size of a coalition and $n^{*}$ the size of a stable coalition, then coalitions for which $n^{*} \geq n \geq 1$ is true are internally stable and those for which $n>n^{*}$ is true are not internally stable. Since for symmetric countries it holds that if $n(n+1)$ is an internally stable (internally unstable) coalition, then $n-1(n)$ is an externally unstable (externally stable) coalition, we can state: coalitions for which $n^{*}>n \geq 1$ are externally unstable and those for which $n \geq n^{*}$ are externally stable. Taken together, coalition $n^{*}$ is internally and externally stable and hence stable.

Second, it is shown that if a minimum participation clause $n^{\#}$ is set above the equilibrium coalition size $n^{*}$ without such a clause, e.g., $n^{\#} \geq n^{*}$, the coalition with $n=n^{\#}$ members is stable. The argument runs as follows. If the number of signatories is $n=n^{\#}$, then this is a stable coalition since leaving the coalition meant that the entire coalition would break apart. This does not pay as the payoff of a signatory with $n=n^{\#}$ members is higher than in the Nash equilibrium with $n=1$. Since any coalition $n \geq n^{*}$ is

50 A similar idea is analyzed in simple matrix games in Ecchia and Mariotti (1998). 
externally stable, $n=n^{\#}$ is stable. It is also argued that a coalition with $n>n^{\#} \geq n^{*}$ members cannot be stable because it is not internally stable and the threat of a complete break-up of the coalition would be lost. Of course, setting the minimum participation strictly below $n^{*}$ cannot be an equilibrium as a coalition for which $n<n^{*}$ is true is not externally stable.

All papers conclude that a minimum participation clause works like a coordination device. It improves upon the prospects of cooperation because global welfare increases with the coalition size and $n^{\#} \geq n^{*}$. Moreover, in Carraro et al. (2004) the choice of the minimum participation clause $n^{\#}$ is endogenized. This basically means to show that all countries are $e x$-ante (without knowing whether they will be a signatory or non-signatory) better off with proposing $n^{\# *}$ than any other proposal $n^{\#} \neq n^{\# *}$. They conclude that for the most common payoff functions countries will agree to set the minimum participation $n^{\# *}$ to full participation.

I go along with this conclusion and also think that these contributions help to explain an institutional feature of actual treaty-making. However, I have two reservations.

First, the question arises whether it is credible to assume that a member in a coalition with $n=n^{\#}>n^{*}$ members should expect that leaving the coalition causes the entire coalition to break up into singletons. After all, all papers conclude that a coalition with $n^{*}$ members is profitable and stable without clause. I also doubt whether a coalition with $n>n^{\#}$ members cannot be stable. If countries are not myopic, then they know that a deviation may trigger further deviations. Hence, if the payoff of a signatory at $n>n^{\#}$ was larger than as a non-signatory at $n=n^{\#}$ deviation would not pay. Hence, a coalition with $n>n^{\#}$ can be stable. This last remark may also help to solve the following puzzle.

Second, as Rutz (2002) points out, in almost all IEAs that he investigated the number of participants exceeds the minimum requirement - a phenomenon which cannot be explained by the models mentioned above. With my small modification, this observation could be accommodated easily.

\section{SUMMARY}

This paper showed that the game theoretic analyses of international environmental agreements (IEAs) can provide interesting and policy relevant insights. This was illustrated with results derived from an empirical climate module linked to a game theoretic module called STACO model in Section 3. The focus was on the impacts of some institutional rules of IEAs (called the design of an agreement) on the success of cooperation. It was argued that qualitative conclusions appear robust as they are confirmed by sensitivity analyses and are also confirmed by the CWS model for a similar set of assumptions. However, it also was pointed out that the STACO model as well as many other current models still leave much room for improvement. Many important aspects of actual treaty making are not captured. On the one hand, this limits the predictive power of these models in the sense of a positive analysis. On the other hand, this implies that not all opportunities for the improvement of stable and successful cooperation have been explored in the sense of a normative analysis. 
For these reasons, the assumptions underlying the results in Section 3 were critically reviewed in Section 4. On the one hand, shortcomings were identified and it was argued why improvements are important as well as possible directions for future research were suggested. On the other hand, some of the literature was reviewed that, at least in a first step, have already addressed some of these shortcomings. It became evident that despite many papers have been written since Mäler's paper on the acid rain game appeared in 1989 , using game theory to study the prospects and limits of cooperation in the context of transboundary environmental externalities, there are still plenty of opportunities to contribute to this avenue of research. In fact, I would argue, there are not only plenty of opportunities, but also a serious need to improve and further develop current models in order to provide policy guidance for the design of future IEAs. The current negotiations about a Post-Kyoto Protocol to tackle the problem of global warming (after the Kyoto Protocol terminates in 2012), with the hope to improve upon participation and enforcement, is currently probably the most prominent example underscoring this need. However, it is and will certainly not remain the only reason why more research on global environmental governance with the tools of game theory will be needed in the future. ${ }^{51}$

\section{REFERENCES}

Altamirano-Cabrera, J.-C. 2007. "On the Political Economy of International Climate Agreements." $\mathrm{PhD}$ thesis, The Netherlands: University of Wageningen.

Altamirano-Cabrera, J.-C. and M. Finus. 2006. "Permit Trading and Stability of International Climate Agreements." Fournal of Applied Economics 9: 19-48.

Altamirano-Cabrera, J. C., M. Finus, and R. Dellink. 2008. "Do Abatement Quotas Lead to More Successful Climate Coalitions?" The Manchester School 76: 104-129.

Asheim, G. B., C. B. Froyn, J. Hovi, and F. C. Menz. 2006. "Regional Versus Global Cooperation for Climate Control." Fournal of Environmental Economics and Management 51(1): 93-109.

Babiker, M. H. 2001. "The $\mathrm{CO}_{2}$ Abatement Game: Costs, Incentives, and the Enforceability of a Sub-global Coalition." Fournal of Economics and Control 25: 1-34.

Babiker, M. H., J. M. Reilly, M. Mayer, R. S. Eckaus, I. Sue Wing, and R. C. Hyman. 2001. "The MIT Emissions Prediction and Policy Analysis (EPPA) Model: Revisions, Sensitivities and Comparison of Results.” Joint Program on the Science and Policy of Global Change Report 71, Cambridge: MIT.

Barrett, S. 1994. "Self-Enforcing International Environmental Agreements." Oxford Economic Papers 46: 878-894.

Barrett, S. 1997. "The Strategy of Trade Sanctions in International Environmental Agreements." Resource and Energy Economics 19: 345-361.

Barrett, S. 1999. "A Theory of Full International Cooperation." Fournal of Theoretical Politics 11(4): $519-541$.

Barrett, S. 2001. “International Cooperation for Sale.” European Economic Reviem 45(10): 1835-1850.

Barrett, S. 2002. “Consensus Treaties.” Journal of Institutional and Theoretical Economics 158: 529-547.

Barrett, S. 2003. Environment and Statecraft: The Strategy of Environmental Treaty-making. New York: Oxford University Press.

51 The scarcity of drinking water from transboundary water sources, overfishing of many species in oceans, and the loss of biodiversity for instance through extensive logging of rain forests are just three examples. 
Bloch, F. 1995. "Endogenous Structures of Associations in Oligopolies." RAND Fournal of Economics 26: $537-556$.

Bloch, F. 2003. "Non-cooperative Models of Coalition Formation in Games with Spillovers." In: ed. C. Carraro, The Endogenous Formation of Economic Coalitions, Cheltenham, UK: Edward Elgar, ch. 2, pp. 35-79.

Böhringer, C. and M. Finus. 2005. "The Kyoto Protocol: Success or Failure?” In Climate-change Policy, ed. D. Helm, Oxford, UK: Oxford Economic Press, ch. 12, pp. 253-281.

Böhringer, C. and A. Löschel. 2006. "Computable General Equilibrium Models for Sustainability Impact Assessment: Status Quo and Prospects.” Ecological Economics 60: 49-64.

Böhringer, C. and C. Vogt. 2004. "The Dismantling of a Breakthrough: The Kyoto Protocol as Symbolic Policy." European Fournal of Political Economy 20: 597-618.

Bosello, F., B. Buchner, and C. Carraro. 2003. "Equity, Development, and Climate Change Control." Fournal of the European Economic Association 1(2-3): 601-611.

Buchner, B. and C. Carraro. 2005a. "Modelling Climate Policy, Perspectives on Future Negotiations." Fournal of Policy Modeling 27: 711-732.

Buchner, B. and C. Carraro. 2005b. "Regional and Sub-global Climate Blocs. A Game-theoretic Perspective on Bottom-up Climate Regimes." Working Paper No. 21. 2005, Milan, Italy: Fondazione Eni Enrico Mattei.

Bucholz, W., A. Haupt, and W. Peters. 2005. "International Environmental Agreements and Strategic Voting." Scandinavian fournal of Economics 107: 175-195.

Buonanno, P., C. Carraro, and M. Galeotti. 2003. "Endogenous Induced Technical Change and the Costs of Kyoto." Resource Energy Economics 25(1): 11-34.

Caparrós, A., J.-C. Péreau, and T. Tazdait. 2004. "North-South Climate Change Negotiations: A Sequential Game with Asymmetric Information.” Public Choice 121: 455-480.

Carraro, C. 2000. "Roads towards International Environmental Agreements." In The Economics of International Environmental Problems, ed. H. Siebert, Tübingen: Mohr Siebeck, pp. 169-202.

Carraro, C., J. Eyckmans, and M. Finus. 2006. "Optimal Transfers and Participation Decisions in International Environmental Agreements." Reviem of International Organizations 1: 379-396.

Carraro, C. and C. Marchiori. 2003. "Stable Coalitions." In The Endogenous Formation of Economic Coalitions, ed. C. Carraro, Cheltenham, UK: Edward Elgar, ch. 5, pp. 156-198.

Carraro, C., C. Marchiori, and S. Oreffice. 2004. "Endogenous Minimum Participation in International Environmental Treaties." CEPR Discussion Paper No. 4281, London.

Carraro, C. and D. Siniscalco. 1993. "Strategies for the International Protection of the Environment." Fournal of Public Economics 52(3): 309-328.

Carraro, C. and D. Siniscalco. 1997. "R\&D Cooperation and the Stability of International Environmental Agreements.” In: ed. C. Carraro, International Environmental Negotiations: Strategic Policy Issues, Cheltenham, UK: Edward Elgar, ch. 5, pp. 71-96.

Carraro, C. and D. Siniscalco. 1998. "International Environmental Agreements: Incentives and Political Economy." European Economic Reviem 42(3-5): 561-572.

Chander, P. and H. Tulkens. 1992. "Theoretical Foundations of Negotiations and Cost Sharing in Transfrontier Pollution Problems.” European Economic Reviem 36(2-3): 388-399.

Chander, P. and H. Tulkens. 1995. "A Core-Theoretic Solution for the Design of Cooperative Agreements on Transfrontier Pollution." International Tax and Public Finance 2(2): 279-293.

Chander, P. and H. Tulkens. 1997. "The Core of an Economy with Multilateral Environmental Externalities." International Journal of Game Theory 26(3): 379-401.

Clarke, H. R. and W. J. Reed. 1994. "Consumption Pollution Tradeoffs in an Environment Vulnerable to Pollution-Related Catastrophic Collapse.” Fournal of Economic Dynamics and Control 18(5): 9911010 .

d'Aspremont, C., A. Jacquemin, J. J. Gabszewicz, and J. A. Weymark. 1983. "On the Stability of Collusive Price Leadership." Canadian Fournal of Economics 16: 17-25.

Dellink, R. B., M. Finus, E. C. van Ierland, and J.-C. Altamirano. 2004. "Empirical background paper of the STACO model." Available on the STACO website http://www.enr.wur.nl/uk/staco, Wageningen University. 
Dellink, R., M. Finus, and N. Oliemann. 2005. "Coalition Formation under Uncertainty: The Stability Likelihood of an International Climate Agreement.” Working Paper No. 98. Italy: Fondazione Eni Enrico Mattei. (Forthcoming: "Fournal of Environmental and Resource Economics".)

Diamantoudi E. and E. Sartzetakis. 2006. "Stable International Environmental Agreements: an Analytical Approach." Fournal of Public Economic Theory 8: 247-263.

Diamantoudi E. and E. Sartzetakis. 2007. International Environmental Agreements - The Role of Foresight. Mimeo: McGill University.

Ecchia, G. and M. Mariotti. 1998. "Coalition Formation in International Environmental Agreements and the Role of Institutions." European Economic Reviem 42(3): 573-582.

Endres, A. 1997. "Negotiating a Climate Convention - The Role of Prices and Quantities." International Reviem of Lam and Economics 17(1): 147-156.

Endres, A. and M. Finus. 2002. "Quotas May Beat Taxes in a Global Emission Game." International Tax and Public Finance 9: 687-707.

Endres, A. and C. Ohl. 2000. "Taxes versus Quotas to Limit Global Environmental Risks: New Insights into an Old Affair." Environmental Economics and Policy Studies 3: 399-423.

Endres, A. and C. Ohl. 2002. "Introducing 'Cooperative Push': How Inefficient Environmental Policy (Sometimes!) Protects the Global Commons Better." Public Choice 111: 285-302.

Endres, A. and C. Ohl. 2003. "International Environmental Cooperation with Risk Aversion." International Journal of Sustainable Development 6: 378-392.

Eyckmans, J. 1999. "Strategy Proof Uniform Effort Sharing Schemes for Transfrontier Pollution Problems." Environmental and Resource Economics 14: 165-189.

Eyckmans, J. 2003. On the Farsighted Stability of International Climate Agreements. Belgium, Mimeo: University of Leuven.

Eyckmans, J. and M. Finus. 2004. "An Almost Ideal Sharing Scheme for Coalition Games with Externalities.” CLIMNEG Working Paper No. 62, Belgium: University of Leuven (K.U.L.). (Also, Working Paper No. 155. Fondazione Eni Enrico Mattei, Italy.)

Eyckmans, J. and M. Finus. 2006a. "New Roads to International Environmental Agreements: The Case of Global Warming." Environmental Economics and Policy Studies 7: 391-414.

Eyckmans, J. and M. Finus. 2006b. "Coalition Formation in a Global Warming Game: How the Design of Protocols Affects the Success of Environmental Treaty-Making." Natural Resource Modeling 19: $323-358$.

Eyckmans, J. and M. Finus. 2007. "Measures to Enhance the Success of Global Climate Treaties." International Environmental Agreements 7: 73-97.

Eyckmans, J. and H. Tulkens. 2003. "Simulating Coalitionally Stable Burden Sharing Agreements for the Climate Change Problem." Resource and Energy Economics 25(4): 299-327.

Finus, M. 2001. Game Theory and International Environmental Cooperation. Cheltenham, UK: Edward Elgar.

Finus, M. 2003a. "Stability and Design of International Environmental Agreements: The Case of Transboundary Pollution." In International Yearbook of Environmental and Resource Economics, 2003/4, eds. H. Folmer and T. Tietenberg, Cheltenham, UK: Edward Elgar, ch. 3, pp. 82-158.

Finus, M. 2003b. "New Developments in Coalition Theory: An Application to the Case of Global Pollution." In Environmental Policy in an International Perspective, eds. L. Marsiliani, M. Rauscher, and C. Withagen, Dordrecht, Holland: Kluwer, pp. 19-49.

Finus, M. 2004. "Modesty Pays: Sometimes!” Working Paper No. 68.04, Milano: Fondazione Eni Enrico Mattei.

Finus, M. 2007. "Possibilities for Cooperation in International Pollution Control." In The Economics of Global Environmental Change International Cooperation for Sustainability, eds. M. Cognoy and K. W. Steininger, Cheltenham, UK: Edward Elgar, ch. 6, pp. 157-195.

Finus, M. and B. Rundshagen. 1998. "Toward a Positive Theory of Coalition Formation and Endogenous Instrumental Choice in Global Pollution Control.” Public Choice 96: 145-186.

Finus, M. and B. Rundshagen. 2003. "Endogenous Coalition Formation in Global Pollution Control: A Partition Function Approach." In Endogenous Formation of Economic Coalitions, ed. C. Carraro, Cheltenham, UK: Edward Elgar, ch. 6, pp. 199-243.

Finus, M. and B. Rundshagen. 2006a. "A Micro-Foundation of Core-Stability in Positive Externality Coalition Games.” Fournal of Institutional and Theoretical Economics 162: 329-346. 
Finus, M. and B. Rundshagen. 2006b. "Participation in International Environmental Agreements: The Role of Timing and Regulation." Natural Resource Modeling 19: 165-200.

Finus, M., E. van Ierland, and J. C. Altamirano-Cabrera. 2005. "The Effect of Membership Rules and Voting Schemes on the Success of International Climate Agreements." Public Choice 125: 95-127.

Finus, M., E. van Ierland, and R. Dellink. 2006. "Stability of Climate Coalitions in a Cartel Formation Game." Economics of Governance 7: 271-291.

Finus, M., M. E. Sáiz, and E. M. T. Hendrix. 2004. "An Empirical Test of New Developments in Coalition Theory for the Design of International Environmental Agreements.” Mansholt Working Paper No. 14, The Netherlands: University of Wageningen.

Finus, M. and S. Tjøtta. 2003. "The Oslo Protocol on Sulfur Reduction: The Great Leap Forward?" Fournal of Public Economics 87: 2031-2048.

Fischer, C., I. W. H. Parry, and W. A. Pizer. 2003. "Instrument Choice for Environmental Protection when Technological Innovation is Endogenous." Fournal of Environmental Economics and Management 45(3): 523-545.

Folmer, H. and P. van Mouche. 2000. “Transboundary Pollution and International Cooperation.” In The International Yearbook of Environmental and Resource Economics, eds. H. Folmer and T. Tietenberg, Cheltenham, UK: Edward Elgar, pp. 231-267.

Folmer, H. and P. van Mouche. 1994. "Interconnected Games and International Environmental Problems II." Annals of Operations Research 54: 97-117.

Folmer, H., P. van Mouche, and S. E. Ragland. 1993. "Interconnected Games and International Environmental Problems." Environmental and Resource Economics 3(4): 313-335.

Folmer, H. and A. de Zeeuw. 1999. "Game Theory in Environmental Policy Analysis." In Handbook of Environmental and Resource Economics, ed. J. C. van den Bergh, Cheltenham, UK: Edward Elgar, ch. 70, pp. 1089-1098.

Folmer, H. and A. de Zeeuw. 2000. "International Environmental Problems and Policy." In Principles of Environmental and Resource Economics: A Guide for Students and Decision-Makers, eds. H. Folmer and H. L. Gabel, Cheltenham, UK: Edward Elgar, pp. 447-478.

Fujita, T. 2004. "Design of International Environmental Agreements und Uncertainty." Environmental Economics and Policy Studies 6: 103-118.

Gjerde, J., S. Grepperud, and S. Kverndokk. 1999. "Optimal Climate Change Policy under the Possibility of Catastrophe.” Resource and Energy Economics 21(3-4): 289-317.

Golombek, R. and M. Hoel. 2005. "Climate Policy under Technology Spillovers." Environmental and Resource Economics 31: 201-227.

Gua, J., C. J. Hepburn, R. S. J. Tol, and D. Anthoff. 2006. "Discounting and the Social Cost of Carbon: A Closer Look at Uncertainty." Environmental Science and Policy 9: 205-216.

Haeringer, G. and Courtois, P. 2005. "The Making of International Environmental Agreements." CODE Working Paper 652.05.

Hanley, N., J. F. Shogren, and B. White. 1997. "Environmental Economics." In Theory and Practice. Houndsmills, UK: MacMillian Press Ltd.

Hoel, M. 1992. "International Environment Conventions: The Case of Uniform Reductions of Emissions." Environmental and Resource Economics 2(2): 141-159.

Hoel, M. and K. Schneider. 1997. "Incentives to Participate in an International Environmental Agreement." Environmental and Resource Economics 9(2): 153-170.

Jeppesen, T. and P. Andersen. 1998. "Commitment and Fairness in Environmental Games." In Game Theory and the Environment, eds. N. Hanley and H. Folmer, Cheltenham, UK: Edward Elgar, ch. 4, pp. $65-83$.

Kempfert, C. 2005. "Induced Technological Change in a Multi-regional, Multi-sectoral, Integrated Assessement Model (WIAGEM): Impact Assessement of Climate Policy Strategies.” Ecological Economics 54: 293-305.

Kolstad, C. D. 1996. "Fundamental Irreversibilities in Stock Externalities.” Fournal of Public Economics 60: 221-233.

Kolstad, C. D. 2007. "Systematic Uncertainty in Self-enforcing International Environmental Agreements." Fournal of Environmental Economics and Managament 53: 68-79. 
Kolstad, C. D. and A. Ulph. 2006. "International Environmental Agreements under Uncertainty when Learning Reveals Differences between Countries." Paper Presented at the Conference Learning and Climate Change, Laxenburg, Austria: IIASA.

Kverndokk, S. and K. E. Rosendahl. 2007. "Climate Policies and Learning by Doing: Impacts and Timing of Technology Subsidies.” Resource and Energy Economics 29(1): 58-82.

Lange, A. 2006. "The Impact of Equity-preferences on the Stability of International Environmental Agreements." Environmental and Resource Economics 34(2): 247-267.

Lange, A. and C. Vogt. 2003. "Cooperation in International Environmental Negotiations due to a Preference for Equity." Fournal of Public Economics 87(9-10): 2049-2067.

Lange, A., C. Vogt, and A. Ziegler. 2007. "On the Importance of Equity in International Climate Policy: An Empirical Analysis.” Energy Economics 29: 545-562.

Mäler, K.-G. 1989. “The Acid Rain Game.” In Valuation Methods and Policy Making in Environmental Economics, eds. H. Folmer and E. C. van Ierland, North-Holland, Amsterdam: Elsevier, ch. 12, pp. 231-252.

Michaelowa, A. 1998. "Climate Policy and Interest Groups - A Public Choice Analysis." Intereconomics 33(6): 251-259.

Murdoch, J. C. and T. Sandler. 1997a. "Voluntary Cutbacks and Pretreaty Behavior: The Helsinki Protocol and Sulfur Emissions." Public Finance Reviem 25(2): 139-162.

Murdoch, J. C. and T. Sandler. 1997b. "The Voluntary Provision of a Pure Public Good: The Case of Reduced CFC Emissions and the Montreal Protocol." Fournal of Public Economics 63(3): 331-349.

Na, S.-L. and H. S. Shin. 1998. "International Environmental Agreements under Uncertainty." Oxford Economic Papers 50: 173-185.

Nordhaus, W. D. and Z. Yang. 1996. "A Regional Dynamic General-Equilibrium Model of Alternative Climate-Change Strategies.” American Economic Reviem 86(4): 741-765.

Peters, W. and C. Schuler. 2006. "International Environmental Agreements: Can Equity and Fairness Enlarge the Size of the Coalition?" Paper presented at the 6th Meeting on Game Theory and Practice, Spain: Zaragoza.

Ray, D. and R. Vohra. 1999. "A Theory of Endogenous Coalition Structures." Games and Economic Behavior 26(2): 286-336.

Ray, D. and R. Vohra. 2001. "Coalitional Power and Public Goods." Fournal of Political Economy 109: $1355-1384$.

Rose, A., B. Stevens, J. Edmonds, and M. Wise. 1998. "International Equity and Differentiation in Global Warming Policy: An Application to Tradeable Emmission Permits." Environmental and Resource Economics 12(1): 25-51.

Rubio, S. J. and B. Casino. 2005. "Self-enforcing International Environmental Agreements with a Stock Pollutant.” Spanish Economic Reviem 7(2): 89-109.

Rubio, S. J. and A. Ulph. 2002. "A Simple Dynamic Model of International Environmental Agreements with a Stock Pollutant." Discussion Papers in Economics No. 209, University of Southampton.

Rubio, S. J. and A. Ulph. 2006. "Self-enforcing International Environmental Agreements Revisited." Oxford Economic Papers 58: 233-263.

Rubio, S. J. and A. Ulph. 2007. "An Infinite-horizon Model of Dynamic Membership of International Environmental Agreements." Journal of Environmental Economics and Management 54: 296-310.

Rutz, S. 2002. "International Environmental Agreements: Much Ado about Nothing?" PhD thesis, Aachen: Shaker Verlag.

Scrieciu, S. S. 2006. "The Inherent Dangers of Using Computable General Equilibrium Models as a Single Integrated Modelling Framework for Sustainability Impact Assessment." A Critical Note on Böhringer and Löschel (2006) 4: 678-684.

Swanson, T. and R. Mason. 2003. "The Impact of International Environmental Agreements: The Case of the Montreal Protocol." In Environmental Policy in an International Perspective, eds. L. Marsiliani, M. Rauscher, and C. Withagen, Dordrecht: Kluwer Academic Publishers, pp. 51-80.

Tol, R. S. J. 2001. "Climate Coalitions in an Integrated Assessment Model." Computational Economics 18(2): 159-172.

Tulkens, H. 1998. "Cooperation versus Free-Riding in International Environmental Affairs: Two Approaches." In Game Theory and the Environment, eds. N. Hanley and H. Folmer, Cheltenham, UK: Edward Elgar, ch. 2, pp. 30-44. 
Ulph, A. 1998. "Learning about Global Warming?" In Game Theory and the Environment, eds. N. Hanley and H. Folmer, Cheltenham, UK: Edward Elgar, ch. 13, pp. 255-286.

Ulph, A. 2004. "Stable International Environmental Agreements with a Stock Pollutant, Uncertainty and Learning." Fournal of Risk and Uncertainty 29(1): 53-73.

Ulph, A. and D. Maddison. 1997. "Uncertainty, Learning and International Environmental Policy Coordination." Environmental and Resource Economics 9: 451-466.

Ulph, A. and D. Ulph. 1997. "Global Warming, Irreversibility and Learning." The Economic Fournal 107: $636-650$.

Wagner, U. J. 2001. "The Design of Stable International Environmental Agreements: Economic Theory and Political Economy." Fournal of Economic Surveys 15(3): 377-411.

Weikard, H.-P., M. Finus and J. C. Altamirano-Cabrera. 2006. "The Impact of Surplus Sharing on the Stability of International Climate Coalitions.” Oxford Economic Papers 58: 209-232.

De Zeeuw, A. 2007. "Dynamic Effects on the Stability of International Environmental Agreements." Fournal of Environmental Economics and Management 55(2): 163-174. 